NBER WORKING PAPER SERIES

\title{
CROWDING OUT IN RICARDIAN ECONOMIES
}

\author{
Andrew B. Abel \\ Working Paper 21550 \\ http://www.nber.org/papers/w21550 \\ NATIONAL BUREAU OF ECONOMIC RESEARCH \\ 1050 Massachusetts Avenue \\ Cambridge, MA 02138 \\ September 2015
}

I thank Joshua Abel and Michael Roberts for helpful discussions and Anna Cororaton for excellent research assistance. The views expressed herein are those of the author and do not necessarily reflect the views of the National Bureau of Economic Research.

NBER working papers are circulated for discussion and comment purposes. They have not been peerreviewed or been subject to the review by the NBER Board of Directors that accompanies official NBER publications.

(C) 2015 by Andrew B. Abel. All rights reserved. Short sections of text, not to exceed two paragraphs, may be quoted without explicit permission provided that full credit, including $\bigcirc$ notice, is given to the source. 
Crowding Out in Ricardian Economies

Andrew B. Abel

NBER Working Paper No. 21550

September 2015

JEL No. E62,G11,H6

\begin{abstract}
$\underline{\text { ABSTRACT }}$
The crowding-out coefficient is the ratio of the reduction in privately-issued bonds to the increase in government bonds that are issued to finance a tax cut. If (1) Ricardian equivalence holds, and (2) households do not simultaneously borrow risklessly and have positive gross positions in other riskless assets, the crowding-out coefficient equals the fraction of the aggregate tax cut that accrues to households that borrow. In the conventional case in which all households receive equal tax cuts, the crowding-out coefficient equals the fraction of households that borrow. In the United States, about $75 \%$ of households borrow, so the crowding-out coefficient is predicted to be 0.75 , which differs from econometric estimates that are around 0.5. I explore extensions of the model, such as a departure from Ricardian Equivalence or the introduction of cross-sectional variation in taxes, that might account for this difference.
\end{abstract}

Andrew B. Abel

The Wharton School

University of Pennsylvania

2315 Steinberg Hall - Dietrich Hall

Philadelphia, PA 19104-6367

and NBER

abel@wharton.upenn.edu 
In the absence of transactions costs, any individual household could increase its holdings of riskless government bonds and reduce its holdings of riskless privately-issued bonds by equal amounts. Such a reallocation of riskless assets in the individual's portfolio might be described as government bonds crowding out an equal value of privately-issued bonds. For an individual household, the crowding-out coefficient, which is the ratio of the decrease in privately-issued bonds to the increase in government bonds, equals one. In a closed economy, however, the household sector as a whole cannot simply increase its aggregate holdings of government bonds. The aggregate supply of government bonds is determined by the fiscal actions of the government-in particular, tax cuts or increases in government purchases will increase the amount of government bonds outstanding, and tax increases or cuts in government purchases will decrease the amount of government bonds outstanding. I will focus on Ricardian tax changes, which are lump-sum changes in current taxes accompanied by offsetting lump-sum changes in future taxes of equal present value. If Ricardian Equivalence holds, then a Ricardian tax cut has no effect on consumption, investment, interest rates, or asset prices. Households will simply use the tax cut to purchase newly-issued government bonds and then will use these bonds, with interest, to pay for increased future taxes levied to enable the government to pay the interest and principal on these bonds. No other net asset positions are affected and hence it would appear that the crowding-out coefficient is zero.

In a closed economy, the net supply of privately-issued bonds is zero and hence if all households are identical, there will be no privately-issued bonds. Barro and Mollerus (2014) introduce privately-issued bonds in a closed economy by allowing households to be heterogeneous, so that some households are borrowers and others are lenders. They present an illuminating numerical example in which Ricardian Equivalence holds and yet each additional dollar of government bonds associated with a Ricardian tax cut will crowd out private bonds by 50 cents, so that the crowding-out coefficient is 0.5. This example clearly refutes the argument above that Ricardian Equivalence implies zero crowding out. ${ }^{1}$

While the value of 0.5 for the magnitude of the crowding-out coefficient is consistent with the empirical findings of Krishnamurthy and Vissing-Jorgenson (2013, p.1) and Gorton, Lewellen and Metrick (2012, Table 1), it is important to note that the value of 0.5 derived by Barro and Mollerus (2014) is simply an example. At the level of economic theory, their framework, which includes Ricardian Equivalence and the restriction that households cannot simultaneously borrow and have positive gross holdings of riskless assets, does not pin down a value of the crowding-out coefficient. In this framework, the crowding out coefficient equals the fraction of the current aggregate tax cut that accrues to

\footnotetext{
${ }^{1}$ In characterizing the novelty of their finding, they state "what is surprising is that this equivalence associates with a crowding-out coefficient for private bonds with respect to public bonds of -0.5, not -1.0." (Barro and Mollerus, 2014, p. 26) However, since their model displays Ricardian Equivalence, the surprising aspect of their finding is that the crowding-out coefficient differs from zero.
} 
households that borrow. That fraction can, in principle, be anywhere between 0 and 1. As I show in this paper, data from the Federal Reserve's Survey of Consumer Finances show that about three quarters of U.S. households borrow. Therefore, the crowding-out coefficient in the model is about 0.75 , rather than 0.5 , under the conventional assumption that all households receive equal lump-sum tax cuts.

Barro and Mollerus (2014) use parametric specifications of household utility and the evolution of output. Looking beyond the particular parametric specifications, the important features of their model are that Ricardian Equivalence holds and that any given household cannot simultaneously issue riskless bonds and hold positive amounts of riskless assets. I adopt these two features but I do not restrict the analysis to particular parametric specifications of the utility function or of the evolution of output. I further generalize the analysis in five ways: (1) rather than assuming equal numbers of borrowers and lenders, I allow an arbitrary cross-sectional distribution of riskless asset positions, including borrowers who have various negative positions in riskless assets and lenders who have various positive positions in riskless assets; (2) I allow for open as well as closed economies; (3) I analyze tax increases as well as tax cuts and show that the crowding-out coefficient for tax increases is greater than or equal to the crowding-out coefficient for tax cuts; (4) I allow tax cuts that are large enough to induce some borrowers to become lenders and tax increases that are large enough to induce some lenders to become borrowers; and (5) I generalize the notion of Ricardian tax changes to allow for cross-household heterogeneity in the size of the current lump-sum tax change.

In a closed economy with identical households, there are no privately-issued bonds. However, in an open economy with identical households, domestic households can issue bonds that will be held by foreigners, and domestic tax cuts can crowd out domestic privately-issued bonds. If all domestic households choose to issue bonds, then a sufficiently small bond-financed tax cut will reduce the amount of bonds issued by domestic households by the amount of the tax cut; the crowding-out coefficient will be 1.0. If the tax cut is as large as the amount of privately-issued bonds initially outstanding, it will completely eliminate privately-issued bonds and the crowding-out coefficient will also be 1.0. Larger tax cuts will also eliminate privately-issued bonds, and the amount of newly-issued government bonds will exceed the reduction in privately-issued bonds. Thus, the crowding-out coefficient will be less than 1.0 for sufficiently large tax cuts. As I show, the crowding-out coefficient in an open economy with identical households can be anywhere between zero and one. ${ }^{2}$

To examine privately-issued bonds in a closed economy requires relaxing the assumption of identical households so that some, but not all, households borrow. I show that if all households receive equal tax cuts, then each additional dollar of government debt will crowd out privately-issued domestic bonds by an amount equal to the fraction of domestic households that are borrowers. That is, the crowding-out coefficent equals the fraction of households that are borrowers. In

${ }^{2}$ More precisely, it can be any rational number between zero and one. 
the examples in Barro and Mollerus (2014), half of the households are borrowers, so the analytic results I derive in this paper indicate that the crowding-out coefficent is 0.5 in those examples.

To obtain an empirical measure of the crowding-out coefficient in the model, both with identical tax changes across households and with cross-household heterogeneity in tax changes, I use data from the Survey of Consumer Finances and from the Congressional Budget Office. I find that in the conventional case in which all households receive identical small tax cuts, the crowding-out coefficient, which simply equals the fraction of households that borrow, is 0.75 . Allowing for realistic heterogeneity in tax changes increases the crowding-out coefficient to 0.85 . The values of 0.75 and 0.85 far exceed the empirical value of 0.5 emphasized by Barro and Mollerus (2014). To address this discrepancy, I introduce a particular departure from Ricardian Equivalence, parametrized by $0 \leq \gamma \leq 1$, where $\gamma=0$ represents Ricardian Equivalence and $\gamma=1$ represents the situation in which households do not change their total holdings of riskless assets at all in response to a bond-financed lump-sum tax cut. It turns out that $\gamma=1 / 3$ reconciles the value of the crowding-out coefficient in the model under the conventional assumption of identical tax changes across households with empirical estimates of the crowding-out coefficient. With cross-household heterogeneity in tax changes, a value of $\gamma=0.412$ reconciles the model with empirical estimates.

I describe the menu of safe assets and safe liabilities in Section 1, and explain the implications of the restriction that individuals will not simultaneously borrow risklessly and hold riskless assets. In Section 2, I define Ricardian tax changes, which lead each household to increase its net position in riskless assets by the amount of the tax cut it receives. I define the crowding-out coefficient in Section 3, and show that it is weakly decreasing in the size of a Ricardian tax cut and weakly increasing in the size of a Ricardian tax increase. Section 4 focusses on the conventional case in which all households receive identical tax cuts. This section also presents a closed-form solution for the crowding-out coefficient in open economies populated by identical households who borrow from foreign lenders. In Section 5, I introduce a class of non-Ricardian economies parametrized by a scalar that measures the departure from Ricardian Equivalence. In Section 6, I use data from the Survey of Consumer Finances to measure the model's crowding-out coefficient if all households receive identical tax cuts. To analyse the crowding-out coefficient when there is cross-sectional variation in tax cuts, I also use data from the Congressional Budget Office on the share of total Federal taxes paid by each quintile of income. Section 7 presents concluding remarks.

\section{Riskless Assets Held by Households}

Consider an open economy populated by a unit measure of domestic households indexed by $i \in[0,1]$. All households of a given type $i$ are identical in all respects. They have identical preferences and have identical opportunities to earn income 
and to hold assets and issue liabilities. Each household optimally chooses consumption and saving and a portfolio of assets that may include both riskless and risky assets and liabilities. In particular, households can hold government bonds, which are riskless and can issue riskless liabilities in the form of bonds. There are no binding constraints on the intertemporal allocation of consumption and Ricardian Equivalence holds. ${ }^{3}$ That is, a bond-financed lump-sum cut in current taxes that is offset by a riskless future lump-sum tax increase of equal present value will have no effect on consumption or asset prices; it will, however, increase households' net positions in riskless assets by an amount equal to the tax cut received.

Let $A(i)$ be the net holding of riskless assets (described below) held by households of type $i$. Households with $A(i)<0$ are borrowers. Define the measure $F(i)$ of households so that $\int_{A(i)<0} d F(i)$ is the fraction of households that are borrowers, that is, issuers of riskless private bonds.

Domestic households of type $i$ may hold four types of riskless assets in the following amounts: (1) $b^{G}(i) \geq 0$ of riskless domestic government bonds, where the non-negativity constraint reflects the fact that households cannot issue government bonds and the assumption that they cannot short government bonds; (2) $b^{P}(i)$ of riskless private bonds issued by domestic households. For domestic households that hold these bonds as assets, their net holdings are $b^{P}(i)>0$, and for domestic households that issue these bonds as liabilities, their net holdings are $b^{P}(i)<0 ;(3) a^{H}(i) \geq 0$ of other domestic riskless assets (the superscript $H$ denotes assets in the home country), such as riskless physical assets, where the non-negativity constraint reflects the assumption that households cannot short physical assets; and (4) $a^{F}(i) \geq 0$ of foreign riskless assets, including foreign-issued riskless bonds, where the non-negativity constraint reflects the assumption that domestic households cannot short foreign assets. Of course, households in an open economy can issue their own riskless bonds, which could be held by foreign agents; such bonds would appear as negative values of $b^{P}(i)$ for domestic households.

Household $i$ 's overall holding of riskless assets, $A(i)$, is

$$
A(i)=a^{H}(i)+a^{F}(i)+b^{G}(i)+b^{P}(i),
$$

where

$$
a^{H}(i) \geq 0, a^{F}(i) \geq 0, b^{G}(i) \geq 0 .
$$

All four riskless assets pay their owners the same interest rate. Therefore, a household's allocation of a given positive total amount of riskless assets, $A(i)>0$, among non-negative holdings of the four types of riskless assets is indeterminate. However, I follow Barro and Mollerus (2014) and assume that individual households will never borrow and lend simultaneously. ${ }^{4}$ Therefore,

\footnotetext{
${ }^{3} \mathrm{I}$ will not specify the utility function other than that utility is an increasing concave function of the household's consumption and does not depend directly on taxes per se or asset holdings per se.

${ }^{4}$ Barro and Mollerus (2014, p. 26) assume that "there is an infinitesimal amount of trans-
} 
$b^{P}(i)$ cannot be negative if any of the other holdings of riskless assets, $a^{H}(i)$, $a^{F}(i)$, and $b^{G}(i)$, are positive. That is,

$$
\begin{aligned}
& b^{P}(i) a^{H}(i) \geq 0 \\
& b^{P}(i) a^{F}(i) \geq 0
\end{aligned}
$$

and

$$
b^{P}(i) b^{G}(i) \geq 0
$$

Lemma 1 Assume that equations (2), (3), (4), and (5) hold.

1. If $b^{P}(i)<0$, then $A(i)=b^{P}(i)<0$ and

2. If $A(i) \leq 0$, then $b^{P}(i)=A(i) \leq 0$.

Lemma 1 implies that a household is a borrower, that is, an issuer of private bonds, if and only if its net holding of riskless assets is negative. Therefore, the aggregate amount of riskless bonds issued by domestic households is

$$
B^{P} \equiv-\int_{A(i)<0} b^{P}(i) d F(i) \geq 0 .
$$

Statement 2 of Lemma 1 directly implies the following corollary, which states that the aggregate amount of riskless bonds issued by domestic households, $B^{P}$, equals the negative of the aggregate value of the net positions in riskless assets of households with $A(i)<0$.

Corollary 1 to Lemma $1 B^{P} \equiv-\int_{A(i)<0} b^{P}(i) d F(i)=-\int_{A(i)<0} A(i) d F(i)$.

In a closed economy, every outstanding privately-issued bond is the liability of some household and an asset of other some other household. Therefore, $\int_{0}^{1} b^{P}(i) d F(i)=$ 0 , so $B^{P} \equiv-\int_{A(i)<0} b^{P}(i) d F(i)=\int_{A(i) \geq 0} b^{P}(i) d F(i)$. That is, in a closed economy, the amount of privately-issued riskless bonds can be measured either as the aggregate amount of these bonds issued by domestic borrowers or as the aggregate amount of these bonds held by domestic lenders. In an open economy, some domestically-issued private riskless bonds may be held by foreign holders, so that $\int_{0}^{1} b^{P}(i) d F(i) \leq 0$. Therefore, in an open economy,

action costs for bond issuance or collection of interest and principal" that prevents individual households from simultaneously borrowing and lending. Under such costs, households may avoid vanishingly small positive or negative positions in riskless assets and their positions in riskless assets may be insensitive to vanishingly small tax changes. To avoid that potential insensitivity, one could assume that households incur a fixed cost if they hold both positive and negative gross positions in riskless assets but do not incur these costs if they hold only one of the these gross positions. That assumption is tantamount to simply assuming that no households simultaneously borrow and lend riskless assets, and I will simply adopt that assumption here. 
the aggregate amount of riskless bonds issued by domestic private borrowers, $B^{P} \equiv-\int_{A(i)<0} b^{P}(i) d F(i)$, will be greater than or equal to the aggregate holding of these bonds by domestic lenders, $\int_{A(i) \geq 0} b^{P}(i) d F(i)$, because foreigners may hold some of these privately-issued domestic bonds. ${ }^{5}$

The aggregate worldwide holding of domestic government bonds is

$$
B^{G, W} \equiv B^{G}+B^{G, F}
$$

where

$$
B^{G} \equiv \int_{0}^{1} b^{G}(i) d F(i) \geq 0
$$

is the aggregate amount of domestic government bonds held by domestic households and $B^{G, F}$ is the aggregate amount of domestic government bonds held by foreigners.

\section{Ricardian Tax Changes}

Consider a tax change that reduces the current lump-sum taxes taxes paid by each household of type $i$ by $\varepsilon z(i)$ and increases that household's future lump-sum taxes by an amount with present value known to equal $\varepsilon z(i)$, where $z(i)>0$. The factor $z(i)$ allows for cross-sectional variation in the size of the current tax cut received by households of different types. I will normalize $z(i)$ so that $\int z(i) d F(i)=1$, which implies that the aggregate reduction in current taxes is $\varepsilon$. If $\varepsilon>0$, then households receive a cut in current taxes and face an increase in future taxes. Alternatively, if $\varepsilon<0$, then households pay increased current taxes and receive a cut in future taxes. In either case, the present value of the current and future taxes paid by each household is unchanged by the tax change. I will call this tax change a Ricardian tax change. ${ }^{6}$

Assume that households do not face any binding constraints on the intertemporal allocation of consumption and that Ricardian Equivalence holds. That is, in response to a Ricardian tax change, households of type $i$ do not change consumption or the holdings of any assets, except that they increase their net holdings of riskless assets, $A(i)$, by $\varepsilon z(i)$ to finance the future tax increase with a present value of $\varepsilon z(i)$. These additional riskless assets are made available by the government, which finances the aggregate tax cut by issuing additional bonds in the amount $\varepsilon$. The following definition formalizes the definition of a Ricardian tax cut in an economy in which Ricardian Equivalence holds.

Definition 1 Under Ricardian Equivalence, a Ricardian tax cut of aggregate size $\varepsilon$ reduces current lump-sum taxes of type $i$ households by $\varepsilon z(i)$, increases

\footnotetext{
${ }^{5}$ Any lending by domestic households to foreign borrowers is represented by $a^{F}(i)>0$.

${ }^{6}$ I will often use the term Ricardian tax cut to include reductions in current lump-sum taxes (so that the tax cut, $\varepsilon$, is positive) as well as increases in current lump-sum taxes (so that the tax cut, $\varepsilon$, is negative). When I restrict attention to the case with $\varepsilon>0$, a Ricardian tax cut will mean that current lump-taxes decline.
} 
their future taxes by an equal present value, and induces them to increase their holdings of riskless assets by $\varepsilon z(i)$.

Note that Definition 1 allows $\varepsilon$ to be negative as well as positive. When $\varepsilon<0$, households pay increased taxes in the current period and receive a tax cut in the future.

Consider an initial situation, before a tax change, and use the subscript 0 to denote the values of variables in this situation. From Corollary 1, the aggregate amount of privately-issued domestic bonds in this initial situation is

$$
B_{0}^{P}=-\int_{A_{0}(i)<0} A_{0}(i) d F(i) .
$$

In response to a Ricardian tax cut of $\varepsilon z(i)$, regardless of whether $\varepsilon$ is positive or negative, households of type $i$ increase their holdings of riskless assets, $A(i)$, by $\varepsilon z(i)$ to

$$
A_{1}(i)=A_{0}(i)+\varepsilon z(i),
$$

and the worldwide amount of domestic government bonds outstanding increases to

$$
B_{1}^{G, W}=B_{0}^{G, W}+\varepsilon
$$

\subsection{Ricardian Tax Cut: Incumbent Borrowers, Former Borrowers, and Incumbent Lenders}

Consider the case with $\varepsilon>0$ so that households receive a cut in their current taxes. It is convenient to put each household into one of three categories depending on whether the household borrows before and after the tax cut (incumbent borrowers), borrows before but not after the tax cut (former borrowers), or does not borrow either before or after the tax cut (incumbent lenders). Household $i$ 's status as an incumbent borrower, former borrower, or incumbent lender depends on $A_{0}(i)$, its position in riskless assets before the tax cut, and on the size of the tax cut, $\varepsilon z(i)$. Households with $A_{0}(i)<-\varepsilon z(i)<0$ initially borrow more than $\varepsilon z(i)$ and have $A_{1}(i)=A_{0}+\varepsilon z(i)<0$ after the tax cut, so they will continue to borrow after the tax cut. Therefore, these households are incumbent borrowers. Households with $-\varepsilon z(i) \leq A_{0}(i)<0$ borrow an amount less than or equal to $\varepsilon z(i)$ before the tax cut, but since $A_{1}(i)=A_{0}(i)+\varepsilon z(i) \geq 0$, they will not borrow after the tax cut. Therefore, these households are former borrowers. Finally, households with $A_{0}(i) \geq 0$ will have $A_{1}(i)>0$ after the tax cut. Hence, they are incumbent lenders since they are lenders after the tax cut and were lenders (more precisely, non-borrowers) before the tax cut. ${ }^{7}$

\footnotetext{
${ }^{7}$ When $A(i)>0$, the allocation of an individual household's riskless assets to the four categories of riskless assets is indeterminate. Any one, two, or three of $a^{F}(i), a^{H}(i), b^{G}(i)$, and $b^{P}(i)$ can be zero. If $a^{F}(i)=b^{G}(i)=b^{P}(i)=0$, then $a^{H}(i)>0$ and strictly speaking the household is not a lender (it does not lend to foreign borrowers, the domestic government, or domestic private borrowers). Nevertheless, for ease of exposition I will use the term "lender" to describe any household with $A(i)>0$.
} 
Consider households that are incumbent borrowers, that is, households with $b_{0}^{P}(i)=A_{0}(i)<-\varepsilon z(i)$. These households are the only domestic private issuers of bonds after the tax cut. After the tax cut, incumbent borrowers of type $i$ have outstanding bonds of $-b_{1}^{P}(i)=-A_{1}(i)=-\left(A_{0}(i)+\varepsilon z(i)\right)$, so the total amount of privately-issued domestic bonds after the tax cut is

$$
B_{1}^{P} \equiv-\int_{A_{0}(i)<-\varepsilon z(i)}\left(A_{0}(i)+\varepsilon z(i)\right) d F(i) .
$$

Before the tax cut the amount of privately-issued domestic bonds is $B_{0}^{P}$ in equation (9), so the reduction in the amount of privately-issued domestic bonds associated with the tax cut can be calulated by subtracting equation (12) from equation (9) to obtain

$$
B_{0}^{P}-B_{1}^{P}=-\int_{A_{0}(i)<0} A_{0}(i) d F(i)+\int_{A_{0}(i)<-\varepsilon z(i)}\left(A_{0}(i)+\varepsilon z(i)\right) d F(i) .
$$

Equation (13) holds both for reductions in current taxes $(\varepsilon>0)$ and increases in current taxes $(\varepsilon<0)$. In the case of tax reductions $(\varepsilon>0)$, it can be rewritten as

$B_{0}^{P}-B_{1}^{P}=-\int_{-\varepsilon z(i) \leq A_{0}(i)<0} A_{0}(i) d F(i)+\varepsilon \int_{A_{0}(i)<-\varepsilon z(i)} z(i) d F(i) \geq 0, \quad$ for $\varepsilon>0$.

$B_{0}^{P}-B_{1}^{P}$ is the amount of privately-issued domestic bonds that are crowded out by the Ricardian tax cut. The first term on the right hand side of equation (14) is the amount bonds initially issued by former borrowers; these former borrowers pay off these bonds completely when they receive the tax cut. The second term is the reduction in bonds issued by incumbent borrowers; these incumbent borrowers each reduce their bonds outstanding by $\varepsilon z(i)$.

\subsection{Ricardian Tax Increases: Incumbent Borrowers, New Borrowers, and Incumbent Lenders}

Now consider the case in which $\varepsilon<0$ so that households of type $i$ face an increase of $-\varepsilon z(i)>0$ in current lump-sum taxes and receive a future lump-sum tax cut with known present value equal to $-\varepsilon z(i)$. After the tax increase, there will be incumbent borrowers, new borrowers, and incumbent lenders. Households with $A_{0}(i)<0$ are incumbent borrowers because they have negative positions in riskless assets before and after the tax increase since $A_{1}(i)=A_{0}(i)+\varepsilon z(i)<$ $A_{0}(i)<0$. Households with $0 \leq A_{0}(i)<-\varepsilon z(i)$ are new borrowers because they had non-negative positions in riskless assets before the tax increase and negative positions $A_{1}(i)=A_{0}(i)+\varepsilon z(i)<0$ after the tax increase. Households with $A_{0}(i) \geq-\varepsilon z(i)>0$ have $A_{1}(i)=A_{0}(i)+\varepsilon z(i) \geq 0$ and thus have nonnegative positions in riskless assets before and after the tax increase; they are incumbent lenders. 
After the tax increase, the total amount of domestic privately-issued debt is given by equation (12), which comprises the negative positions, $A_{0}(i)+\varepsilon z(i)$, of incumbent borrowers $\left(A_{0}(i)<0\right)$ and new borrowers $\left(0 \leq A_{0}(i)<-\varepsilon z(i)\right)$. Therefore, the reduction in domestic privately-issued bonds, $B_{0}^{P}-B_{1}^{P}$ is given by equation (13). ${ }^{8}$ Rearranging equation (13) under that assumption that $\varepsilon<0$ yields

$$
B_{0}^{P}-B_{1}^{P}=\int_{0 \leq A_{0}(i)<-\varepsilon z(i)} A_{0}(i) d F(i)+\int_{A_{0}(i)<-\varepsilon z(i)} \varepsilon z(i) d F(i) \text {, for } \varepsilon<0 .
$$

\subsection{Shares of the Aggregate Tax Change}

The impact of Ricardian tax changes depends on the shares of the aggregate tax change accruing to borrowers of various types. To simplify notation, I will define the function $G(a ; Z)$ to compactly represent the share of the aggregate tax change that accrues to households with initial positions in riskless assets less than $a z(i)$. Specifically, let $Z$ represent the cross-sectional distribution of $z(i)>0$ and define

$$
G(a ; Z) \equiv \int_{\frac{A_{0}(i)}{z(i)}<a} z(i) d F(i)
$$

as the share of the aggregate tax cut $\varepsilon$ that is received by households with initial positions in riskless assets, $A_{0}(i)$, less than $a z(i)$. Observe that $G(a ; Z)$ is (weakly) increasing in $a$. Recall from Lemma 1 that if $A(i) \leq 0$, then $b^{P}(i)=A(i)$. Therefore, if $a \leq 0$, then $G(a ; Z) \equiv \int_{\frac{A_{0}(i)}{z(i)}<a} z(i) d F(i)=$ $\int_{\frac{b_{0}^{P}(i)}{z(i)}<a} z(i) d F(i)$, which is the fraction of the aggregate tax cut $\varepsilon$ that is received (or, if $\varepsilon<0$, the fraction of the aggregate tax increase paid) by households with initial net holdings of domestic privately-issued bonds less than $a z(i) \leq 0$. Therefore, $G(0 ; Z)$ is the fraction of the aggregate tax change that accrues to or from households that are borrowers before the tax cut. After the tax cut, the set of borrowers is the set for which $A_{1}(i)=A_{0}+\varepsilon z(i)<0$, or equivalently, $\frac{A_{0}}{z(i)}<-\varepsilon$. Therefore, $G(-\varepsilon ; Z)$ is the fraction of the aggregate tax change that accrues to housholds that are borrowers after the tax cut.

If, as in standard analyses of Ricardian Equivalence, there is no crosssectional variation in changes in current taxes or in futures taxes, then $z(i) \equiv 1$. I will use the notation $G(a ; \mathbf{1})$ to denote the value of $G(a ; Z)$ in this case. It follows immediately from the definition of $G(a ; Z)$ that $G(a ; \mathbf{1})=\int_{A_{0}(i)<a} d F(i)$, so that $G(0 ; \mathbf{1})$ is the fraction of households that are borrowers before the tax change and $G(-\varepsilon ; \mathbf{1})$ is the fraction of households that are borrowers after the tax change. Therefore, in the case of a current tax cut, $\varepsilon>0, G(-\varepsilon ; \mathbf{1})$ is the

\footnotetext{
${ }^{8}$ Equation (15) can be rearranged as $B_{0}^{P}-B_{1}^{P}=\int_{0 \leq A_{0}(i)<-\varepsilon z(i)}\left(A_{0}(i)+\varepsilon z(i)\right) d F(i)+$ $\int_{A_{0}(i)<0} \varepsilon z(i) d F(i)$. Since $\varepsilon<0$, both integrals on the right hand side are non-positive and hence the reduction in domestic privately-issued bonds is non-positive. That is, the amount of these bonds increases or remains unchanged.
} 
fraction of households that are incumbent borrowers, and $G(0 ; \mathbf{1})-G(-\varepsilon ; \mathbf{1}) \geq 0$ is the fraction of households that are former borrowers. Alternatively, in the case of a current tax increase, $\varepsilon<0, G(0 ; \mathbf{1})$ is the fraction of households that are incumbent borrowers, and $G(-\varepsilon ; \mathbf{1})-G(0 ; \mathbf{1}) \geq 0$ is the fraction of households that are new borrowers.

\section{The Crowding-Out Coefficient}

Define $\theta(\varepsilon)$ to be the crowding-out coefficient associated with a Ricardian tax cut of size $\varepsilon \neq 0$. If $\varepsilon>0$, then $\theta(\varepsilon)$ is the reduction in the amount of privatelyissued domestic bonds divided by the amount of additional domestic government bonds outstanding, $\varepsilon$. Alternatively, if $\varepsilon<0$, then $\theta(\varepsilon)$ is the increase in privately-issued domestic bonds divided by the decrease in government bonds outstanding. Formally,

Definition 2 The crowding-out coefficient associated with a Ricardian tax cut of size $\varepsilon \neq 0$ is $\theta(\varepsilon) \equiv \frac{1}{\varepsilon}\left(B_{0}^{P}-B_{1}^{P}\right)$. For vanishingly small tax changes, define $\theta\left(0^{+}\right) \equiv \lim _{\varepsilon \backslash 0} \theta(\varepsilon)$ and $\theta\left(0^{-}\right) \equiv \lim _{\varepsilon}{ }_{0} \theta(\varepsilon)$.

The following lemma presents an expression for the crowding-out coefficient that follows directly from substituting equation (13) into Definition 2.

Lemma 2 The crowding-out coefficient associated with a Ricardian tax cut of size $\varepsilon \neq 0$ is $\theta(\varepsilon)=\frac{1}{\varepsilon}\left(-\int_{A_{0}(i)<0} A_{0}(i) d F(i)+\int_{A_{0}(i)<-\varepsilon z(i)} A_{0}(i) d F(i)\right)+$ $\int_{A_{0}(i)<-\varepsilon z(i)} z(i) d F(i)$.

Lemma 2 provides an exact expression for the crowding-out coefficient as a function of $\varepsilon$. In this section, I analyze properties of this function.

Proposition 1 If $\varepsilon>0$, then $G(-\varepsilon ; Z) \leq \theta(\varepsilon) \leq G(0 ; Z)$. If $\varepsilon<0$, then $G(0 ; Z) \leq \theta(\varepsilon) \leq G(-\varepsilon ; Z)$.

Proposition 1, which is proved in the Appendix, states that the crowdingout coefficient lies in the closed interval between $G(-\varepsilon ; Z)$ and $G(0 ; Z)$. In the case of a tax cut, $\varepsilon>0$, so $G(-\varepsilon ; Z) \leq G(0 ; Z)$. Therefore, the closed interval between $G(-\varepsilon ; Z)$ and $G(0 ; Z)$ is $[G(-\varepsilon ; Z), G(0 ; Z)]$. In this case, $G(-\varepsilon ; Z)$ is the fraction of the tax cut accruing to incumbent borrowers. Each incumbent borrower reduces borrowing by the amount of the tax cut, so the total amount of bonds issued by incumbent borrowers falls by $\varepsilon G(-\varepsilon ; Z)$. Therefore, the crowding-out coefficient is at least $G(-\varepsilon ; Z)$. The fraction of the tax cut accruing to former borrowers is $G(0 ; Z)-G(-\varepsilon ; Z)$, but former borrowers reduce their borrowing by no more than $\varepsilon(G(0 ; Z)-G(-\varepsilon ; Z))$, so that the total borrowing of incumbent borrowers and former borrowers is reduced by no more than $\varepsilon G(-\varepsilon ; Z)+\varepsilon(G(0 ; Z)-G(-\varepsilon ; Z))=\varepsilon G(0 ; Z)$. Therefore, the crowding-out coefficient is no greater than than $G(0 ; Z)$. 
In the case of a tax increase, $\varepsilon<0$, so $G(0 ; Z) \leq G(-\varepsilon ; Z)$. Therefore, the closed interval between $G(-\varepsilon ; Z)$ and $G(0 ; Z)$ is $[G(0 ; Z), G(-\varepsilon ; Z)]$. In this case, $G(0 ; Z)$ is the fraction of the tax increase paid by incumbent borrowers. Since each incumbent borrower increases borrowing by the amount of the tax increase, total borrowing by incumbent borrowers increases by $-\varepsilon G(0 ; Z)>0$. Therefore, the overall amount of privately-issued bonds outstanding increases by at least $-\varepsilon G(0 ; Z)>0$, so the crowding-out coefficient is at least $G(0 ; Z)$. The fraction of the tax increase paid by new borrowers is $G(-\varepsilon ; Z)-G(0 ; Z)$, but new borrowers borrow no more than $-\varepsilon(G(-\varepsilon ; Z)-G(0 ; Z))$, so that the total borrowing of incumbent borrowers and new borrowers increases by no more than $-\varepsilon G(0 ; Z)-\varepsilon(G(-\varepsilon ; Z)-G(0 ; Z))=-\varepsilon G(-\varepsilon ; Z)$. Therefore, the crowding-out coefficient is no greater than $G(-\varepsilon ; Z)$.

Proposition $2 \quad \theta(\varepsilon)$ is (weakly) decreasing in $\varepsilon \neq 0$.

Proposition 2 states that the crowding-out coefficient, $\theta(\varepsilon)$, is (weakly) decreasing in the aggregate size of a tax cut, $\varepsilon>0$, but is (weakly) increasing in the aggregate size of a tax increase $-\varepsilon>0$. First consider a tax cut. Increasing the size of the tax cut, $\varepsilon$, induces more initial borrowers to pay off all of their outstanding bonds and to become former borrowers. Further increases in the tax cut cannot further reduce the debt issued by these households since they have already paid off their debt. Put differently, a tax cut reduces the amount of bonds outstanding by less for households that become former borrowers than for households that become incumbent borrowers. Since larger tax cuts induce more households to become former borrowers and reduce the measure of incumbent borrowers, the crowding-out coefficient, $\theta(\varepsilon)$, is smaller for larger tax cuts.

Now consider a tax increase. Increasing the size of the tax increase, $-\varepsilon>0$, induces some households that were not borrowers before the tax increase to become new borrowers after the tax increase. These new borrowers do not reduce the measure of incumbent borrowers, all of whom increase their borrowing by the amount of their increased taxes. Therefore, these new borrowers increase the amount of privately-issued domestic bonds outstanding by more than the increase in borrowing from the incumbent borrowers. Since larger tax increases induce more households to become new borrowers, without reducing the measure of incumbent borrowers, the crowding-out coefficient $\theta(\varepsilon)$ is larger for larger tax increases.

Proposition 2 immediately implies the following corollary.

Corollary 2 Starting from a given initial situation, the crowding-out coefficient for tax increases is at least as large as the crowding-out coefficient for tax cuts, with strict inequality for large tax changes.

The following proposition presents expressions for the crowding-out coefficients for vanishingly small tax cuts, $\theta\left(0^{+}\right) \equiv \lim _{\varepsilon \backslash 0} \theta(\varepsilon)$, and vanishingly small tax increases, $\theta\left(0^{-}\right) \equiv \lim _{\varepsilon \succ 0} \theta(\varepsilon)$. 
Proposition $3 \theta\left(0^{+}\right)=G(0 ; Z) \leq G\left(0^{+} ; Z\right)=\theta\left(0^{-}\right)$, where $G\left(0^{+} ; Z\right) \equiv$ $\lim _{x \backslash 0} G(x ; Z)$.

Proposition 3 states that for a vanishingly small tax cut, the crowding-out coefficient, $\theta\left(0^{+}\right)$, equals $G(0 ; Z)$, the fraction of the aggregate tax cut that accrues to households that are borrowers before the tax cut. The aggregate amount of the tax cut that accrues to incumbent borrowers is $\varepsilon G(-\varepsilon ; Z)$ and these incumbent borrowers reduce their borrowing by $\varepsilon G(-\varepsilon ; Z)$. The aggregate amount of the tax cut that accrues to former borrowers is $\varepsilon(G(0 ; Z)-G(-\varepsilon ; Z))$. For a sufficiently small tax cut $\varepsilon>0$, the measure of former borrowers is vanishingly small and the aggregate reduction in domestic privately-issued bonds is $\varepsilon G(0 ; Z)$. Dividing this reduction in privately-issued bonds outstanding by the increase in government bonds outstanding, $\varepsilon$, yields the crowding-out coefficient, $\theta\left(0^{+}\right)=G(0 ; Z)$.

For a tax increase of size $-\varepsilon>0$, each incumbent borrower issues additional bonds in the amount of the additional tax paid. In the aggregate, incumbent borrowers issue $-\varepsilon G(0 ; Z)$ additional bonds after the tax increase. New borrowers issue bonds in the amount of the increased taxes they pay, $-\varepsilon[G(-\varepsilon ; Z)-G(0 ; Z)]$, less their initial non-negative holdings of riskless assets, $\int_{0 \leq A_{0}(i)<-\varepsilon z(i)} A_{0}(i) d F(i)=-\varepsilon \int_{0 \leq A_{0}(i)<-\varepsilon z(i)} \frac{A_{0}(i)}{-\varepsilon z(i)} z(i) d F(i)$. Therefore, the total increase in the amount of bonds issued by incumbent borrowers and new borrowers is $-\varepsilon G(-\varepsilon ; Z)+\varepsilon \int_{0 \leq A_{0}(i)<-\varepsilon z(i)} \frac{A_{0}(i)}{-\varepsilon z(i)} z(i) d F(i)$. Dividing this amount of newly-issued bonds by the aggregate tax increase, $-\varepsilon$, and taking the limit as $\varepsilon$ approaches zero from below, yields $\theta\left(0^{-}\right)=\lim _{\varepsilon / 0} G(-\varepsilon ; Z)=$ $\lim _{\varepsilon \backslash 0} G(\varepsilon ; Z) \equiv G\left(0^{+} ; Z\right)$.

The crowding-out coefficient for a small tax cut, $\theta\left(0^{+}\right)$, will exceed the crowding-out coefficient for a small tax increase, $\theta\left(0^{-}\right)$, if $G(0 ; Z)<G\left(0^{+} ; Z\right)$, that is, if a non-infinitesimal share of the aggregate tax change is paid by or accrues to households with initial riskless assets precisely equal to zero. In this situation, this positive mass of households are incumbent lenders in the event of a tax cut, but are new borrowers in the case of a tax increase. As new borrowers, they further increase the amount by which privately-issued domestic bonds increase in addition to the increase in bonds issued by incumbent borrowers. Therefore, if there is a positive mass of households with precisely zero riskless assets in the initial situation, the crowding-out coefficient for a tax increase exceeds the crowding-out coefficient for a tax cut, even if the tax changes are small.

\section{Identical Tax Changes for All Households}

Conventional analyses of Ricardian Equivalence typically assume that all households receive identical lump-sum tax changes. Definition 1 broadens the concept of Ricardian tax changes to allow for cross-sectional variation in tax changes. Of course, this more expansive definition includes the conventional case in 
which all households receive identical tax change. Formally, the case with identical tax changes for all households is represented by $Z=\mathbf{1}$, so that $G(a ; Z)=G(a ; \mathbf{1})=\int_{A_{0}(i)<a} d F(i)$ is the fraction of households with initial riskless assets, $A_{0}(i)$, less than $a$. Therefore, $G(0 ; \mathbf{1})$ is the fraction of households that are borrowers before the tax cut. After a tax cut of size $\varepsilon>0$, a fraction $G(-\varepsilon ; \mathbf{1})$ of households become incumbent borrowers and a fraction $G(0 ; \mathbf{1})-G(-\varepsilon ; \mathbf{1})$ of households become former borrowers.

The framework used in Barro and Mollerus (2014) is a special case of the framework I develop here. In particular, their analysis adopts the conventional assumption that $Z=\mathbf{1}$ and explicitly restricts attention to tax cuts that are small enough that no borrowers receive a tax cut larger than their initial outstanding bonds. ${ }^{9}$ That is, all of the initial borrowers become incumbent borrowers after the tax cut. In this case, Proposition 3 implies that the crowding-out coefficient, $\theta\left(0^{+}\right)$, equals $G(0 ; \mathbf{1})$, which is the fraction of households that are borrowers before the tax cut. Barro and Mollerus (2014) present an example (plus a second example in footnote 12) in which half of the households are borrowers and half are lenders. Since $G(0 ; \mathbf{1})=0.5$ in this example, the calculated crowding-out coefficient is 0.5 .

\subsection{Closed Economies with Identical Small Tax Cuts for All Households}

Now consider the case of a closed economy in which all households receive identical tax cuts $\varepsilon>0$, and assume that $\varepsilon$ is vanishingly small so that all households that borrow before the tax cut continue to borrow after the tax cut. Again, this case is consistent with the framework in Barro and Mollerus (2014) and the crowding-out coefficient equals $G(0 ; \mathbf{1})$. In principle, the value of $G(0 ; \mathbf{1})$ can be calculated in two different ways. Perhaps the more obvious calculation is simply to identify whether or not each household borrows, and then to compute $G(0 ; \mathbf{1})$ as the fraction of households that borrow. An alternative calculation is based on the ratio of the average amount borrowed by borrowing households to the average amount of lending by lending households. I will develop that calculation in this subsection.

Define

$$
\overline{b^{-}} \equiv \frac{-\int_{b^{P}(i)<0} b^{P}(i) d F(i)}{\int_{b^{P}(i)<0} d F(i)}
$$

as the average amount of bonds issued per household in the set of households

\footnotetext{
${ }^{9}$ Barro and Mollerus (2014, p. 26) assume "that the gross quantity of private bonds outstanding was initially greater than $50 \%$ of the added government bonds." Since borrowers receive $50 \%$ of the aggregate tax reductions, their assumption is that the tax reduction is small enough that borrowers' taxes fall by an amount no larger than their initial issuance of bonds.
} 
that borrow and

$$
\overline{b^{+}} \equiv \frac{\int_{b^{P}(i)>0} b^{P}(i) d F(i)}{\int_{b^{P}(i)>0} d F(i)}
$$

as the average amount of privately-issued domestic bonds held per household in the set of domestic households that lend. In a closed economy, the total amount of bonds issued by households that borrow, $G(0 ; \mathbf{1}) \overline{b^{-}}$, equals the total amount of privately-issued domestic bonds held by housholds that lend, $\left(1-G\left(0^{+} ; \mathbf{1}\right)\right) \overline{b^{+}}$, that is,

$$
G(0 ; \mathbf{1}) \overline{b^{-}}=\left(1-G\left(0^{+} ; \mathbf{1}\right)\right) \overline{b^{+}} .
$$

Equation (19) leads to the following proposition.

Proposition 4 Consider a closed economy with nonzero private borrowing. If all households receive identical tax cuts, i.e., if $Z=\mathbf{1}$, then

$$
\theta\left(0^{+}\right)=\frac{1-\omega_{0}}{1+\lambda} \text { and } \theta\left(0^{-}\right)=\frac{1+\omega_{0} \lambda}{1+\lambda},
$$

where $\lambda \equiv \overline{\overline{b^{-}}}$is the ratio of the average amount of bonds issued by borrowing households to the average amount of privately-issued domestic bonds held by lending households before the tax cut, and $\omega_{0} \equiv G\left(0^{+} ; \mathbf{1}\right)-G(0 ; \mathbf{1})$ is the measure of households that have zero positions in riskless assets before the tax cut.

Proposition 4 applies to any distribution of bond holdings in a closed economy. Remarkably, for any distribution of bond holdings, the crowding-out coefficients $\theta\left(0^{+}\right)$and $\theta\left(0^{-}\right)$in a closed economy are simple functions of two parameters: $\omega_{0}$, which is the measure of households that neither issue nor hold privately-issued bonds before the tax change; and $\lambda$, which is a measure of the asymmetry of the distribution of holdings of riskless bonds.

If $\omega_{0}=0$, so that there is a zero measure of households that neither issue nor hold privately-issued bonds before the tax change, then $\theta\left(0^{+}\right)=\theta\left(0^{-}\right)$is simply $\frac{1}{1+\lambda}$. If, in addtion, the distribution is symmetric, so that $\lambda=1$, the crowding-out coefficient is simply $\theta\left(0^{+}\right)=\theta\left(0^{-}\right)=0.5$. However, if $\omega_{0}>0$, then $\theta\left(0^{+}\right)=\frac{1-\omega_{0}}{2}$ and $\theta\left(0^{-}\right)=\frac{1+\omega_{0}}{2}$ for any symmetric distribution of bond holdings. Therefore, symmetry alone is not sufficient for either $\theta\left(0^{+}\right)$or $\theta\left(0^{-}\right)$ to equal 0.5. In the examples in Barro and Mollerus (2014), both $\lambda=1$ and $\omega_{0}=0$, by assumption, so $\theta\left(0^{+}\right)=\theta\left(0^{-}\right)=0.5$.

\subsection{Open Economies with Identical Households}

In this section I derive a simple expression for the crowding-out coefficient in open economies in which all domestic households have identical preferences, face identical taxes, and have identical opportunities to hold and issue assets. With 
no heterogeneity in households, there is no need to index household holdings of riskless assets, $A(i)$, by $i$, so I will use $A$ to denote the riskless asset holdings of the representative household. Therefore, $A=a^{H}(i)+a^{F}(i)+b^{G}(i)+b^{P}(i)$, where I have retained the household type $i$ in the individual components of $A$ because households do not need to have identical holdings each of the four types of riskless assets. They may choose different combinations of $a^{H}(i)$, $a^{F}(i), b^{G}(i)$, and $b^{P}(i)$ provided that they sum to $A$ and satisfy equations (2), $(3),(4)$, and (5).

Lemma 3 If $A(i)=A \geq 0$ for all $i$, then $b^{P}(i)=0$ for all $i$.

Lemma 3 implies that there are no domestic privately-issued bonds if $A(i)=$ $A \geq 0$ in an economy with identical households. Therefore, to analyze domestic privately-issued bonds in a homogeneous-household framework, I will confine attention to situations in which $A(i)=A<0$ for all $i$. Lemma 1 implies that $b^{P}(i)=A(i)=A<0$ for all $i$. In a closed economy, of course, $b^{P}(i)$ cannot be negative for all $i$, because some domestic households would have to lend to the borrowing households, and there would be no domestic lending households when households are homogeneous. However, in an open economy domestic households can borrow from abroad, in which case $b^{P}(i)=A(i)=A<0$ for all $i$. I will use $b^{P}<0$ to indicate the amount of bonds issued by each domestic household.

The aggregate amount of domestic privately-issued bonds in an open economy with identical households is

$$
B^{P}=\max [-A, 0] \geq 0 .
$$

That is, if $A \geq 0$, there are no privately-issued domestic bonds (Lemma 3), and if $A<0, B^{P}=-A$, since $b^{P}(i)=A(i)=A$. In the initial situation, before the tax cut, the aggregate amount of bonds issued by domestic households is

$$
B_{0}^{P}=\max \left[-A_{0}, 0\right] \geq 0 .
$$

A Ricardian tax cut of size $\varepsilon>0$ increases $A$ by $\varepsilon$ to $A_{0}+\varepsilon$, so the aggregate amount of domestic privately-issued bonds after the tax cut is

$$
B_{1}^{P}=\max \left[-\left(A_{0}+\varepsilon\right), 0\right] \geq 0 .
$$

Subtract equation (22) from equation (21) and rearrange to obtain

$$
B_{0}^{P}-B_{1}^{P}=\min \left[A_{0}+\varepsilon, 0\right]-\min \left[A_{0}, 0\right] .
$$

The crowding-out coefficient, $\theta(\varepsilon) \equiv \frac{1}{\varepsilon}\left(B_{0}^{P}-B_{1}^{P}\right)$, is calculated by dividing equation (23) by the size of the aggregate tax cut $\varepsilon$. For expositional clarity, I will examine the crowding-out coefficients for tax cuts $(\varepsilon>0)$ and tax increases $(\varepsilon<0)$ separately. For tax cuts, equation (23) implies

$$
\begin{aligned}
& 0, \quad \text { if } A_{0} \geq 0 \\
& \text { for } \varepsilon>0, \quad \theta(\varepsilon)=-\frac{A_{0}}{\varepsilon}<1, \quad \text { if } \varepsilon>-A_{0}>0 .
\end{aligned}
$$


If $A_{0} \geq 0$, then there are no privately-issued domestic riskless bonds before or after the tax cut. Therefore, the crowding-out coefficient for $\varepsilon>0$ is zero if $A_{0} \geq 0$. If $\varepsilon>-A_{0}>0$, then $A_{1}=A_{0}+\varepsilon>0$, so households borrow (from foreign lenders) before the tax cut but lend after the tax cut because the tax cut is larger than the amount of privately-issued domestic bonds outstanding before the tax cut. Therefore, the crowding-out coefficient is positive but smaller than one in this case. More precisely, the tax cut eliminates all privatelyissued domestic bonds so that the reduction in these bonds is $-A_{0}$, while the increase in government bonds is $\varepsilon$. Therefore, the crowding-out coefficient is $-\frac{A_{0}}{\varepsilon}<1$. If $-A_{0} \geq \varepsilon$, each household receives a tax cut $\varepsilon>0$ that is smaller than the amount of bonds it has outstanding before the tax cut. Therefore, these households reduce their borrowing by the full amount of the tax cut and the crowding-out coefficient equals one.

For tax increases, equation (23) implies

$$
\begin{aligned}
& 0, \quad \text { if } A_{0} \geq-\varepsilon>0
\end{aligned}
$$

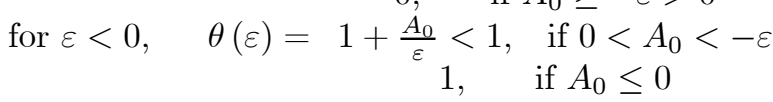

If $A_{0} \geq-\varepsilon>0$, households hold non-negative positions in riskless assets both before the tax increase $\left(A_{0}>0\right)$ and after the tax increase $\left(A_{0}+\varepsilon \geq 0\right)$. Since they have no bonds outstanding either before the tax increase or after the tax increase, the crowding-out coefficient is zero. If $0<A_{0}<-\varepsilon$, households have positive positions in riskless assets before the tax increase but negative positions in riskless assets $\left(A_{0}+\varepsilon<0\right)$ after the tax increase. Therefore, the amount of privately-issued domestic bonds increases by $-\left(A_{0}+\varepsilon\right)$ while government bonds decrease by $-\varepsilon$, so the crowding-out coefficient is $1+\frac{A_{0}}{\varepsilon}<1$. If $A_{0} \leq 0$, then households issue additional bonds to pay for the entire tax increase, so the crowding-out coefficient equals one.

\section{The Crowding-Out Coefficient in a Non-Ricardian Economy}

In a Ricardian economy, when households of type $i$ receive a tax cut of $\varepsilon z(i)$ accompanied by an increase in future taxes with present value $\varepsilon z(i)$, they increase their current holdings of riskless assets by the amount of the tax cut, $\varepsilon z(i)$. Now consider a departure from this Ricardian framework and suppose that all households increase their holdings of riskless assets by a fraction $1-\gamma$ of the tax cut they receive, that is, households of type $i$ increase $A(i)$ by $(1-\gamma) \varepsilon z(i)$, where $0 \leq \gamma \leq 1$. For instance, households may (for unspecified reasons) increase their current consumption by a fraction $\gamma$ of the tax cut and use the remainder of the tax cut to increase their holdings of riskless assets. When $\gamma=0$ Ricardian

Equivalence holds, but when $\gamma>0$, Ricardian Equivalence fails to hold. The parameter $\gamma$ serves as a measure of the departure from Ricardian equivalence. 
Definition 3 Define $\Theta_{N}(\varepsilon, \gamma) \equiv \frac{1}{\varepsilon}\left(B_{0}^{P}-B_{1}^{P}\right)$ as the non-Ricardian crowdingout coefficient associated with a tax cut of aggregate size $\varepsilon \neq 0$, in which households of type $i$ receive a tax cut of $\varepsilon z(i)$ and increase their holdings of riskless assets by $(1-\gamma) \varepsilon z(i)$, where $0 \leq \gamma \leq 1$. For vanishingly small tax changes, define $\Theta_{N}\left(0^{+}, \gamma\right) \equiv \lim _{\varepsilon \backslash 0} \Theta_{N}(\varepsilon, \gamma)$ and $\Theta_{N}\left(0^{-}, \gamma\right) \equiv \lim _{\varepsilon / 0} \Theta_{N}(\varepsilon, \gamma)$.

The amount of riskless assets held by households of type $i$ after increasing their holdings of riskless assets by $(1-\gamma) \varepsilon z(i)$ in response to a tax cut of $\varepsilon z(i)$ is $A_{1}(i)=A_{0}(i)+(1-\gamma) \varepsilon z(i)$. Therefore, the total amount of domestic privately-issued bonds outstanding after the tax cut is

$B_{1}^{P}=-\int_{A_{1}(i)<0} b_{1}^{P}(i) d F(i)=-\int_{A_{0}(i)+(1-\gamma) \varepsilon z(i)<0}\left[A_{0}(i)+(1-\gamma) \varepsilon z(i)\right] d F(i)$.

First consider the case in which $\varepsilon>0$. In this case, subtracting $B_{1}^{P}$ in equation (26) from $B_{0}^{P}$ in equation (9), and rearranging, yields the reduction in the amount of private bonds outstanding

$$
B_{0}^{P}-B_{1}^{P}=\begin{aligned}
& (1-\gamma) \varepsilon \int_{A_{0}(i)<-(1-\gamma) \varepsilon z(i)} z(i) d F(i) \\
& -\int_{-(1-\gamma) \varepsilon z(i) \leq A_{0}(i)<0} A_{0}(i) d F(i)
\end{aligned}, \quad \text { if } \varepsilon>0 .
$$

Households with $A_{0}(i)<-(1-\gamma) \varepsilon z(i) \leq 0$ are incumbent borrowers because they had negative positions in riskless assets before the tax cut and continue to have negative positions in riskless assets, $A_{1}(i)=A_{0}(i)+(1-\gamma) \varepsilon z(i)<$ 0 , after the tax cut. The first term on the right hand side of equation (27) is the reduction in outstanding bonds issued by incumbent borrowers because each of these households reduces its outstanding bonds by $(1-\gamma) \varepsilon z(i)$. Households with $-(1-\gamma) \varepsilon z(i) \leq A_{0}(i)<0$ are former borrowers because they had negative positions in riskless assets before the tax cut and non-negative positions in riskless assets, $A_{1}(i)=A_{0}(i)+(1-\gamma) \varepsilon z(i) \geq 0$, after the tax cut. The second term on the right hand side of equation (27) is the reduction in outstanding bonds issued by former borrowers because each of these households completely pays off its initially outstanding bonds of $-A_{0}(i)$.

Now consider the case in which $\varepsilon<0$, so that taxes increase. Subtracting $B_{0}^{P}$ in equation (9) from $B_{1}^{P}$ in equation (26), and rearranging, yields the increase in the amount of privately-issued domestic bonds outstanding following the tax increase

$B_{1}^{P}-B_{0}^{P}=\begin{gathered}-(1-\gamma) \varepsilon \int_{A_{0}(i)<0} z(i) d F(i) \\ -\int_{0 \leq A_{0}(i)<-(1-\gamma) \varepsilon z(i)}\left[A_{0}(i)+(1-\gamma) \varepsilon z(i)\right] d F(i)\end{gathered} \quad$ if $\varepsilon<0$.

Households with $A_{0}(i)<0$ are incumbent borrowers because they had negative positions in riskless assets before the tax increase and increase their borrowing by $-(1-\gamma) \varepsilon>0$ after the tax increase. The first term on the right hand side of equation (28) is the increase in outstanding bonds issued by incumbent borrowers. Households with $0 \leq A_{0}(i)<-(1-\gamma) \varepsilon z(i)$ are new borrowers 
because $0 \leq A_{0}(i)$ implies that these households did not borrow before the tax increase; however, $A_{0}(i)<-(1-\gamma) \varepsilon z(i)$ implies that these households have negative net holdings of riskless assets, $A_{1}(i)=A_{0}(i)+(1-\gamma) \varepsilon z(i)<0$, after the tax increase, and hence become borrowers after the tax increase. The second term in the right hand side of equation (28) is the aggregate amount of bonds issued by the new borrowers after the tax increase.

Proposition $5 \Theta_{N}(\varepsilon, \gamma)=(1-\gamma) \theta((1-\gamma) \varepsilon)$ for $\varepsilon \neq 0$. For vanishingly small tax changes, $\Theta_{N}\left(0^{+}, \gamma\right) \equiv \lim _{\varepsilon \backslash 0} \Theta_{N}(\varepsilon, \gamma)=(1-\gamma) \theta\left(0^{+}\right)$and $\Theta_{N}\left(0^{-}, \gamma\right)$ $\equiv \lim _{\varepsilon}{ }_{0} \Theta_{N}(\varepsilon, \gamma)=(1-\gamma) \theta\left(0^{-}\right)$.

Proposition 5 applies to tax increases $(\varepsilon<0)$ as well as to tax cuts $(\varepsilon>0)$. For vanishingly small tax changes, the non-Ricardian crowding-out coefficient is simply the Ricardian crowding-out coefficient multiplied by $(1-\gamma)$.

\section{The Crowding-Out Coefficient in the United States}

In this section I present empirical measures of the crowding-out coefficient in the model developed here, and I compare these measures to existing econometric estimates of the crowding-out coefficient. Let $\widehat{\theta}$ denote an econometric estimate of the crowding-out coefficient. Barro and Mollerus (2014) refer specifically to such estimates by Krishnamurthy and Vissing-Jorgenson (2013) and Gorton, Lewellen, and Metrick (2012) and summarize their findings as $\widehat{\theta}=0.5$. I will analyze the extent to which the framework in this paper can account for that value of the crowding-out coefficient. First I present measures of $\theta(\varepsilon)$ under the conventional assumption that all households receive identical lump-sum tax cuts and then I present measures under the more general assumption of crosssectional heterogeneity in tax cuts. Consistent with the assumption in Barro and Mollerus (2014), I focus on tax cuts that are small enough that no households become former borrowers after the tax cut. Formally, this assumption implies that the crowding-out coefficient of interest is $\theta\left(0^{+}\right)=G(0 ; Z)$, which is the fraction of the aggregate tax cut that is received by households that borrow.

In the conventional case in which all households receive identical tax cuts, $z(i) \equiv 1$ for all $i$ and hence $\theta\left(0^{+}\right)=G(0 ; \mathbf{1})$, which is simply the fraction of households that are borrowers. Table 1 , presents, at three-year intervals from 1989 to 2013, the percentage of households that are borrowers. ${ }^{10}$ The values of $G(0 ; \mathbf{1})$ for these years are shown in the final column of Table 1 and range from $72.3 \%$ to $77.0 \%$ over this 24 -year period. That is, the values of $G(0 ; \mathbf{1})$ are fairly tightly clustered around 0.75 .

\footnotetext{
${ }^{10}$ The data are taken from the Federal Reserve's triennial Survey of Consumer Finances as reported in its 2013 Chartbook (unnumbered page 834 of the pdf file downloaded from http://www.federalreserve.gov/econresdata/scf/files/BulletinCharts.pdf.)
} 


\begin{tabular}{|c|c|c|c|c|c||c|}
\hline \multicolumn{7}{|c|}{ Percentage of Households That Borrow, $100 \times \boldsymbol{\beta}_{j}$} \\
\hline & Lowest & Second & Middle & Fourth & Highest & All: $G(0 ; \mathbf{1})$ \\
\cline { 2 - 7 } & Income & Income & Income & Income & Income & $=(1 / 5) \sum \beta_{j}$ \\
\hline Year & Quintile & Quintile & Quintile & Quintile & Quintile & $(\times 100)$ \\
\hline 1989 & 47.1 & 59.5 & 78.1 & 86.2 & 90.7 & $\mathbf{7 2 . 3}$ \\
\hline 1992 & 48.9 & 65.8 & 79.1 & 84.8 & 87.5 & $\mathbf{7 3 . 2}$ \\
\hline 1995 & 49.2 & 68.6 & 79.4 & 87.4 & 88.2 & $\mathbf{7 4 . 5}$ \\
\hline 1998 & 47.3 & 66.8 & 79.9 & 87.3 & 88.9 & $\mathbf{7 4 . 1}$ \\
\hline 2001 & 49.3 & 70.2 & 82.1 & 85.6 & 88.4 & $\mathbf{7 5 . 1}$ \\
\hline 2004 & 52.6 & 69.8 & 84.0 & 86.6 & 89.1 & $\mathbf{7 6 . 4}$ \\
\hline 2007 & 51.7 & 70.2 & 83.8 & 90.9 & 88.6 & $\mathbf{7 7 . 0}$ \\
\hline 2010 & 52.5 & 66.8 & 81.8 & 86.9 & 86.7 & $\mathbf{7 4 . 9}$ \\
\hline 2013 & 52.1 & 66.5 & 81.0 & 87.2 & 85.9 & $\mathbf{7 4 . 5}$ \\
\hline
\end{tabular}

Table 1: Percentage of Households That Borrow. The final column is the percentage of borrowers in the overall population, as reported in the 2013 Chartbook of the Federal Reserve's Survey of Consumer Finances. It may differ from the average of the reported values for the five income quintiles due to rounding.

It is instructive to compare the value of 0.75 for $\theta\left(0^{+}\right)=G(0 ; \mathbf{1})$ reported here to the value of 0.5 reported by Barro and Mollerus (2014). Why does the value reported here exceed theirs by $50 \%$ ? After all, their framework is a special case of the framework presented here. The fundamental economics in both cases is the same: (1) Ricardian Equivalence is assumed to hold and (2) households are not allowed to borrow and hold positive gross amounts of riskless assets simultaneously. Under these assumptions, the value of the crowding-out coefficient associated with small tax cuts is $G(0 ; \mathbf{1})$, which, in principle, can take any value in the unit interval. Some additional information is needed to pin down a particular value in this interval. Barro and Mollerus (2014) present two simple examples in which half of the households are borrowers and the other half are lenders, so $G(0 ; \mathbf{1})=0.5$ by assumption. To be clear, there is no empirical basis nor is there a compelling theoretical reason for $G(0 ; \mathbf{1})$ to be 0.5 . It is, of course, true that in a closed economy the amount of dollars borrowed risklessly equals the amount of dollars lent risklessly, but that does not imply that the number of borrowers equals the number of lenders or that $G(0 ; \mathbf{1})$ equals 0.5 . The size of $G(0 ; \mathbf{1})$ is an empirical magnitude and the data from the Survey of Consumer Finances indicate that $G(0 ; \mathbf{1})$ is tightly clustered around 0.75 . The fact that the value of 0.5 derived by Barro and Mollerus (2014) matches $\widehat{\theta}=0.5$ is a fortuitous coincidence.

The framework developed in this paper can yield a crowding-out coefficient of 0.5 in the conventional case in which all households receive identical tax cuts 


\begin{tabular}{|c|c|c|c|c|c||c|}
\hline \multicolumn{7}{|c|}{ Percentage of Total Federal Tax Liabilities, $100 \times \boldsymbol{\tau}_{j}$} \\
\hline & Lowest & Second & Middle & Fourth & Highest & All: $G(0 ; Z)$ \\
\cline { 2 - 7 } & Income & Income & Income & Income & Income & $=\sum \beta_{j} \tau_{j}$ \\
\hline Year & Quintile & Quintile & Quintile & Quintile & Quintile & $(\times 100)$ \\
\hline 1989 & 1.7 & 6.4 & 12.6 & 20.9 & 58.3 & $\mathbf{8 5 . 3}$ \\
\hline 1992 & 1.9 & 6.2 & 12.2 & 20.4 & 59.1 & $\mathbf{8 3 . 6}$ \\
\hline 1995 & 1.6 & 5.8 & 11.5 & 19.6 & 61.2 & $\mathbf{8 5 . 0}$ \\
\hline 1998 & 1.4 & 5.3 & 10.5 & 18.5 & 64.1 & $\mathbf{8 5 . 7}$ \\
\hline 2001 & 1.3 & 5.0 & 10.1 & 18.6 & 64.8 & $\mathbf{8 5 . 6}$ \\
\hline 2004 & 1.2 & 4.7 & 9.8 & 17.9 & 66.2 & $\mathbf{8 6 . 6}$ \\
\hline 2007 & 1.2 & 4.7 & 9.4 & 16.8 & 67.8 & $\mathbf{8 7 . 1}$ \\
\hline 2010 & 0.4 & 3.8 & 9.1 & 17.6 & 68.8 & $\mathbf{8 5 . 1}$ \\
\hline
\end{tabular}

Table 2: Percentage of Federal Tax Liabilities

by considering a non-Ricardian economy of the sort introduced in Section 5 . Specifically, Proposition 5 implies that if $z(i) \equiv 1$, the crowding-out coefficient for small tax cuts is $\Theta_{N}\left(0^{+}, \gamma\right)=(1-\gamma) \theta\left(0^{+}\right)=(1-\gamma) G(0 ; \mathbf{1})$, where $\gamma$ indicates the degree of departure from Ricardian Equivalence. The crowdingout coefficient $\Theta_{N}\left(0^{+} ; \gamma\right)$ will match the econometrically estimated value $\widehat{\theta}$ if $1-\gamma=\frac{\widehat{\theta}}{G(0 ; \mathbf{1})}$. Since $\widehat{\theta}=0.5$ and $G(0 ; \mathbf{1})=0.75$, the implied value of $\gamma$ is $\gamma=\frac{1}{3}$, which is a substantial departure from Ricardian Equivalence.

\subsection{Cross-Sectional Heterogeneity in Tax Cuts}

To derive an empirical measure of the crowding-out coefficient in the case of heterogeneous tax cuts, I will partition the households in the Survey of Consumer Finances into 10 sets by partitioning each quintile of the income distribution into a set consisting of households that borrow and a set consisting of households that do not borrow. Let $\beta_{j}$ denote the fraction of households in the $j-t h$ income quintile that borrow; the measure of these households is $\beta_{j} / 5$, and the measure of households in the $j-t h$ income quintile that do not borrow is $\left(1-\beta_{j}\right) / 5$. Let $T_{j}$ be the average amount of Federal taxes paid by each household in the $j-t h$ income quintile, so that total taxes paid by households in the $j-t h$ income quantile is $T_{j} / 5$. Therefore, the aggregate amount of Federal taxes paid by all households, $T$, is $T=\sum_{j=1}^{5} T_{j} / 5$. Since there is a unit measure of households in the economy, the economy-wide average amount of taxes per household also equals $T$. Finally, define $\tau_{j} \equiv \frac{T_{j} / 5}{T}=T_{j} / \sum_{i=1}^{5} T_{i}$ as the fraction of aggregate taxes that are paid by household in the $j-t h$ income quintile.

Consider a lump-sum tax cut of aggregate size $\varepsilon$. For now, assume that all households $i$ in the $j-t h$ income quintile receive identical tax cuts $\varepsilon z(i)=5 \tau_{j} \varepsilon$. 
Consistent with the assumption that the economy-wide average value of $z(i)$ equals one, it is straightforward to verify that the aggregate size of the tax cut is $\int \varepsilon z(i) d F(i)=\sum_{j=1}^{5} \frac{1}{5}\left(5 \tau_{j} \varepsilon\right)=\varepsilon$. Since the measure of households that are both in the $j-t h$ income quintile and are borrowers is $\beta_{j} / 5$, the definition of $G(a ; Z) \equiv \int_{\frac{A(i)}{z(i)}<a} z(i) d F(i)$ implies that the fraction of the aggregate tax cut accruing to households that borrow is $G(0 ; Z)=\int_{\frac{A(i)}{z(i)}<0} z(i) d F(i)=$ $\frac{1}{\varepsilon} \sum_{j=1}^{5}\left(\beta_{j} / 5\right)\left(5 \tau_{j} \varepsilon\right)=\sum_{j=1}^{5} \beta_{j} \tau_{j}$. Table 1 reports the values of $\beta_{j}$, the percentage of the $j-t h$ income quintile that borrows, for $j=1,2,3,4,5$, for each year of the triennial Survey of Consumer Finances from 1989 to 2013. Table 2 reports the values of $\tau_{j}$, the percentage of total Federal tax liabilities paid by the $j-t h$ income quantile. These data are from the Congressional Budget Office and they do not include the year 2013. Therefore, Table 2 presents data for each year of the Survey of Consumer Finances from 1989 to 2010. The final column of Table 2 reports the value of $G(0 ; Z)=\sum_{j=1}^{5} \beta_{j} \tau_{j}$, which is the value of $\theta\left(0^{+}\right)$, in each of the displayed years. The values of $G(0 ; Z)$ are tightly clustered around 0.85 , ranging from 0.836 to 0.871 . Allowing for cross-sectional heterogeneity in tax cuts increases the value of the crowding-out coefficient $\theta\left(0^{+}\right)=G(0 ; Z)$ by about 0.10 from its value of the 0.75 when all households receive identical tax cuts. Taking account of heterogeneity in tax cuts increases the crowding-out coefficient because the propensity for a household to borrow and the share of the aggregate tax cut received by a household both monotonically increase in income across income quintiles. That is, $\beta_{j}$ and $\tau_{j}$ are positively correlated across quintiles so that $\sum_{j=1}^{5} \frac{1}{5} \beta_{j} \tau_{j}-\left(\sum_{j=1}^{5} \frac{1}{5} \beta_{j}\right)\left(\sum_{j=1}^{5} \frac{1}{5} \tau_{j}\right)>0$, which implies $G(0 ; Z)=\sum_{j=1}^{5} \beta_{j} \tau_{j}>\left(\sum_{j=1}^{5} \frac{1}{5} \beta_{j}\right)\left(\sum_{j=1}^{5} \tau_{j}\right)=\frac{1}{5} \sum_{j=1}^{5} \beta_{j}=G(0 ; \mathbf{1})$.

The value of 0.85 for $G(0 ; Z)$ exceeds the econometrically estimated value $\widehat{\theta}$ by 0.35 . In the presence of heterogeneous tax cuts, the crowding-out coefficient $\Theta_{N}\left(0^{+} ; \gamma\right)$ will match the econometrically estimated value $\widehat{\theta}$ if $1-\gamma=\frac{\widehat{\theta}}{G(0 ; Z)}$. Since $\widehat{\theta}=0.5$ and $G(0 ; Z)=0.85$, the implied value of $\gamma$ is $\gamma=0.412$, again a substantial departure from Ricardian Equivalence.

\subsubsection{Different Tax Cuts for Borrowers and Non-Borrowers within Income Quintiles}

I have assumed so far that all households in a given income quintile receive identical tax cuts, or more generally, that within a given quintile, the size of the tax cut received by individual households is independent of whether the household is a borrower or not. To the extent that there is a systematic difference in tax cuts received by borrowers and by non-borrowers within an income quintile, the value of $G(0 ; Z)$ will differ from $\sum_{j=1}^{5} \beta_{j} \tau_{j}$. Since the value of $G(0 ; Z)=\sum_{j=1}^{5} \beta_{j} \tau_{j}$, which is 0.85 , substantially exceeds $\widehat{\theta}=0.5$, I will explore systematic differences in taxes paid by borrowers and by nonborrowers that may reduce the calculated value of $G(0 ; Z)$. This exploration 
will illustrate the degree to which the assumption that tax cuts are independent of borrowing status could possibly overstate $G(0 ; Z)$.

Let $T_{j, B}$ be the average tax cut received by each borrowing household in the $j$ - th income quintile and let $T_{j, N}$ be the average tax cut received by each non-borrowing household in the $j-t h$ income quintile. Since a fraction $\beta_{j}$ of the households in the $j-t h$ income quantile are borrowers and a fraction $1-\beta_{j}$ are non-borrowers,

$$
\beta_{j} T_{j, B}+\left(1-\beta_{j}\right) T_{j, N}=T_{j}, \quad \text { for } j=1,2,3,4,5 .
$$

Instead of assuming that $T_{j, N}=T_{j, B}$, as above, now assume that

$$
T_{j, N}=\eta T_{j, B}, \quad \text { for } j=1,2,3,4,5,
$$

with $\eta>0$. Substitute equation (30) into equation (29) and rearrange to obtain

$$
T_{j, B}=\frac{T_{j}}{\beta_{j}+\left(1-\beta_{j}\right) \eta}, \quad \text { for } j=1,2,3,4,5 .
$$

If all households in a given income quintile pay identical taxes, then $\eta=1$, and $T_{j, B}=T_{j}$. However, if $\eta>1$, then $T_{j, B}<T_{j}$ and if $\eta<1$, then $T_{j, B}>T_{j}$.

The tax cut received by each borrowing household $i$ in the $j-t h$ income quintile is $z(i) \varepsilon=\frac{5 \tau_{j} \varepsilon}{\beta_{j}+\left(1-\beta_{j}\right) \eta}$. Since the measure of households that are in the $j-t h$ income quintile and are borrowers is $\beta_{j} / 5$, the definition of $G(a ; Z) \equiv$ $\int_{\frac{A(i)}{z(i)}<a} z(i) d F(i)$ implies that the fraction of the aggregate tax cut accruing to households that borrow is $G(0 ; Z)=\int_{\frac{A(i)}{z(i)}<0} z(i) d F(i)=\sum_{j=1}^{5}\left(\beta_{j} / 5\right) \frac{5 \tau_{j}}{\beta_{j}+\left(1-\beta_{j}\right) \eta}$ $=\sum_{j=1}^{5} \frac{\beta_{j}}{\beta_{j}+\left(1-\beta_{j}\right) \eta} \tau_{j}$. Since $\sum_{j=1}^{5} \frac{\beta_{j}}{\beta_{j}+\left(1-\beta_{j}\right) \eta} \tau_{j}$ is strictly decreasing in $\eta>0$ for $0<\beta_{j}<1$ and $\tau_{j}>0$, an increase in $\eta$ decreases the calculated value of $G(0 ; Z)$. That is, an increase in $\eta$ for a given value of $T_{j}$ reduces the tax cut received by each borrower in the $j-t h$ income quintile. Table 3 reports the value of $G(0 ; Z)$ for 2010 using the values of $\beta_{j}$ and $\tau_{j}$ from tables 1 and 2 , respectively, and various values of $\eta$. The values of $G(0 ; Z)$ in Table 3 fall monotonically as $\eta$ increases, as noted above. Of course, when $\eta=1$, all households in a given quintile receive identical tax cuts, and the value of $G(0 ; Z)$ is identical to its value in the final row and final column of Table 2. Note that for $\eta=6$, the value of $G(0 ; Z)$ equals 0.500 . That is, in order for the calculated value of the crowding-out coefficient to equal $\widehat{\theta}=0.5$, the average tax cut received by non-borrowing households in a given income quintile would have be 6 times as large as the average tax cut received by borrowing households in that same income quintile. Such dramatic within-income-quintile variation in tax changes is far from the spirit of the sort of lump-sum taxes typically associated with Ricardian tax changes. 


\begin{tabular}{|l|c|c|c|c|c|c|c|c|}
\hline \multicolumn{7}{|c|}{ Within-Quintile Heterogenous Taxes: $\boldsymbol{T}_{j, N}=\boldsymbol{\eta} \boldsymbol{T}_{j, B}$} \\
\hline$\eta$ & 0.5 & 1 & 2 & 3 & 4 & 5 & 6 & 10 \\
\hline$G(0 ; Z)$ & 0.918 & 0.851 & 0.745 & 0.663 & 0.598 & 0.544 & 0.500 & 0.377 \\
\hline
\end{tabular}

Table 3: Within-Quintile Heterogenous Taxes

\section{Conclusion}

I have analyzed the crowding-out coefficient under two assumptions: (1) Ricardian equivalence holds so that all households increase their positions in riskless assets by the amount of the current lump-sum tax cut they receive; and (2) no household will simultaneously borrow and hold positive amounts of any riskless assets. Under these two assumptions, the crowding-out coefficient for small tax cuts equals the fraction of the aggregate current tax cut that accrues to households that borrow. That fraction can be any rational number in the unit interval. Existing analyses of Ricardian equivalence typically add a third assumption: (3) all households receive identical tax cuts in the current period. Imposing this third assumption, in addition to the two assumptions listed above, implies that the crowding-out coefficient equals the fraction of households that borrow. Using data from the Survey of Consumer Finances, I have shown that this fraction is about 0.75 , so the three assumptions together imply that the crowding-out coefficient should be 0.75 . However, empirical estimates of the crowding-out coefficient cited by Barro and Mollerus (2014) put the econometrically estimated value of the crowding-out coefficient at 0.5 .

One can view the disparity between the value of 0.75 implied by the three assumptions and the value of 0.5 that is econometrically estimated to be an informal rejection of the joint hypothesis that all three assumptions hold. This disparity also invites investigation of how departures from these assumptions would change the value of the crowding-out coefficient in the model. In this paper, I have explored departures from the first and third assumptions. Specifically, if one replaces the first assumption by an assumption that all households increase their positions in riskless assets by two-thirds - rather than the full amount - of the current lump-sum tax cut they receive, the model predicts a crowding-out coefficient of 0.5 , which matches the econometrically-estimated value. This departure from assumption (1), formally setting $\gamma=1 / 3$ in the model, is a substantial departure from Ricardian Equivalence. Indeed, if one is willing to maintain assumptions (2) and (3), then this departure from $\gamma=0$ could be viewed a rejection of Ricardian Equivalence.

I also explored the effect of departing from assumption (3), while maintaining assumptions (1) and (2) intact. Specifically, I have replaced the assumption that all households receive identical lump-sum tax increases with the assumption that all households receive a tax increase in proportion to the share of aggregate taxes paid by their own income quintile. Because, households in higher income quintiles pay higher taxes per household and have a higher incidence of borrowing, this modification increases the crowding-out coefficient in the model. That 
is, it exacerbates the discrepancy between the model and the econometricallyestimated crowding-out coefficient. The crowding-out coefficient in the model could be reduced by assuming that within each income quintile, non-borrowing households pay higher taxes than borrowing households. In fact, if each nonborrowing household receives a tax cut six times as large as the tax cut received by each borrowing household in its own income quintile, then the model predicts a crowding-out coefficient of 0.5. However, such a large disparity of tax cuts within income quintiles seems counter to the spirit of the tax changes that are the focus of Ricardian Equivalence.

Future research might usefully be directed at relaxing the second of three assumptions above. That is, it may prove fruitful to allow households in the model to borrow and hold positive gross positions in riskless assets at the same time. The challenge is to understand and tractably model the determinants of a household's simultaneous riskless borrowing and holding of positive gross positions in riskless assets. In addition, further extensions of the model could go beyond household balance sheets to examine the assets and liabilities held simultaneously by financial intermediaries. 


\section{Appendix}

Proof. of Lemma 1. Proof of statement 1: If $b^{P}(i)<0$, then equations (2), (3), (4), and (5) imply $a^{H}(i)=a^{F}(i)=b^{G}(i)=0$, so equation (1) implies $A(i)=b^{P}(i)<0$. Proof of statement 2: If $A(i)<0$, then $b^{P}(i)<0$, which implies $a^{H}(i)=a^{F}(i)=b^{G}(i)=0$, so $b^{P}(i)=A(i)<0$. If $A(i)=0$, then $b^{P}(i)$ cannot be negative because if $b^{P}(i)$ were negative, then statement 1 would imply $A(i)=b^{P}(i)<0$, which would contradict $A(i)=0$. If $A(i)=$ 0 , then $b^{P}(i)$ cannot be positive because equations (1) and (2) would imply $A(i) \geq b^{P}(i)>0$, which contradicts $A(i)=0$. Therefore, if $A(i)=0$, then $b^{P}(i)=0=A(i)$.

Proof. of Proposition 1. First consider the case in which $\varepsilon>0$. Substitute equation (14) into the definition of the crowding-out coefficient to obtain

$$
\theta(\varepsilon)=G(-\varepsilon ; Z)+\int_{-\varepsilon z(i) \leq A_{0}(i)<0} \frac{-A_{0}(i)}{\varepsilon z(i)} z(i) d F(i) \geq G(-\varepsilon ; Z),
$$

where the inequality follows from the fact that $\frac{-A_{0}(i)}{\varepsilon z(i)}>0$ for $-\varepsilon z(i) \leq A_{0}(i)<$ 0 . Use

$$
\begin{aligned}
& \int_{-\varepsilon z(i) \leq A_{0}(i)<0} \frac{-A_{0}(i)}{\varepsilon z(i)} z(i) d F(i) \\
= & \int_{-\varepsilon z(i) \leq A_{0}(i)<0}\left(\frac{-A_{0}(i)}{\varepsilon z(i)}-1+1\right) z(i) d F(i) \\
= & -\int_{-\varepsilon z(i) \leq A_{0}(i)<0}\left(1+\frac{A_{0}(i)}{\varepsilon z(i)}\right) z(i) d F(i)+(G(0 ; Z)-G(-\varepsilon ; Z))
\end{aligned}
$$

to rewrite

$$
\theta(\varepsilon)=G(-\varepsilon ; Z)+\int_{-\varepsilon z(i) \leq A_{0}(i)<0} \frac{-A_{0}(i)}{\varepsilon z(i)} z(i) d F(i)
$$

as

$$
\theta(\varepsilon)=G(0 ; Z)-\int_{-\varepsilon z(i) \leq A_{0}(i)<0}\left(1+\frac{A_{0}(i)}{\varepsilon z(i)}\right) z(i) d F(i) \leq G(0 ; Z),
$$

where the inequality follows from the fact $1+\frac{A_{0}(i)}{\varepsilon z(i)} \geq 0$ for $-\varepsilon z(i) \leq A_{0}(i)<0$. Therefore, $G(-\varepsilon ; Z) \leq \theta(\varepsilon) \leq G(0 ; Z)$, if $\varepsilon>0$.

Now consider the case in which $\varepsilon<0$. Substitute equation (15) into the definition of the crowding-out coefficient to obtain

$$
\begin{aligned}
\theta(\varepsilon) & =\frac{1}{\varepsilon} \int_{0 \leq A_{0}(i)<-\varepsilon z(i)} A_{0}(i) d F(i)+\int_{A_{0}(i)<-\varepsilon z(i)} z(i) d F(i) \\
& \leq \int_{A_{0}(i)<-\varepsilon z(i)} z(i) d F(i)=G(-\varepsilon ; Z)
\end{aligned}
$$


where the inequality follows from the fact that $\varepsilon<0$, so that $\frac{1}{\varepsilon} \int_{0 \leq A_{0}(i)<-\varepsilon z(i)} A_{0}(i) d F(i)$ $\leq 0$. Use the fact that

$$
\begin{aligned}
\int_{0 \leq A_{0}(i)<-\varepsilon z(i)} \frac{A_{0}(i)}{\varepsilon} d F(i)= & \int_{0 \leq A_{0}(i)<-\varepsilon z(i)}\left(\frac{A_{0}(i)}{\varepsilon z(i)}+1-1\right) z(i) d F(i) \\
= & \int_{0 \leq A_{0}(i)<-\varepsilon z(i)}\left(\frac{A_{0}(i)}{\varepsilon z(i)}+1\right) z(i) d F(i) \\
& -\int_{0 \leq A_{0}(i)<-\varepsilon z(i)} z(i) d F(i)
\end{aligned}
$$

to rewrite

$$
\theta(\varepsilon)=\frac{1}{\varepsilon} \int_{0 \leq A_{0}(i)<-\varepsilon z(i)} A_{0}(i) d F(i)+\int_{A_{0}(i)<-\varepsilon z(i)} z(i) d F(i)
$$

as

$$
\begin{aligned}
\theta(\varepsilon) & =\int_{0 \leq A_{0}(i)<-\varepsilon z(i)}\left(\frac{A_{0}(i)}{\varepsilon z(i)}+1\right) z(i) d F(i)+\int_{A_{0}(i)<0} z(i) d F(i) \\
& \geq \int_{A_{0}(i)<0} z(i) d F(i)=G(0 ; Z),
\end{aligned}
$$

where the inequality follows from the fact that for $0 \leq A_{0}(i)<-\varepsilon z(i), \frac{A_{0}(i)}{-\varepsilon z(i)}$ $<1$, so that $1+\frac{A_{0}(i)}{\varepsilon z(i)}>0$. Therefore, $G(0 ; Z) \leq \theta(\varepsilon) \leq G(-\varepsilon ; Z)$, if $\varepsilon<0$.

Proof. of Proposition 2. First, consider $\varepsilon_{2}>\varepsilon_{1}>0$. Use the expression for $\theta(\varepsilon)$ in Lemma 2 to obtain

$$
\theta(\varepsilon)=-\frac{1}{\varepsilon} \int_{-\varepsilon z(i) \leq A_{0}(i)<0} A_{0}(i) d F(i)+\int_{A_{0}(i)<-\varepsilon z(i)} z(i) d F(i), \quad \text { for } \varepsilon>0 .
$$

Evaluate $\theta(\varepsilon)$ at $\varepsilon_{1}$ and $\varepsilon_{2}$ and rearrange to obtain

$$
\begin{aligned}
\theta\left(\varepsilon_{1}\right)= & \int_{A_{0}(i)<-\varepsilon_{2} z(i)} z(i) d F(i) \\
& +\int_{-\varepsilon_{2} z(i) \leq A_{0}(i)<-\varepsilon_{1} z(i)} z(i) d F(i) \\
& -\frac{1}{\varepsilon_{1}} \int_{-\varepsilon_{1} z(i) \leq A_{0}(i)<0} A_{0}(i) d F(i)
\end{aligned}
$$

and

$$
\begin{aligned}
\theta\left(\varepsilon_{2}\right)= & \int_{A_{0}(i)<-\varepsilon_{2} z(i)} z(i) d F(i) \\
& -\frac{1}{\varepsilon_{2}} \int_{-\varepsilon_{2} z(i) \leq A_{0}(i)<-\varepsilon_{1} z(i)} A_{0}(i) d F(i) \\
& -\frac{1}{\varepsilon_{2}} \int_{-\varepsilon_{1} z(i) \leq A_{0}(i)<0} A_{0}(i) d F(i) .
\end{aligned}
$$


Subtract $\theta\left(\varepsilon_{2}\right)$ from $\theta\left(\varepsilon_{1}\right)$ and rearrange to obtain

$$
\begin{aligned}
\theta\left(\varepsilon_{1}\right)-\theta\left(\varepsilon_{2}\right)= & \int_{-\varepsilon_{2} z(i) \leq A_{0}(i)<-\varepsilon_{1} z(i)}\left[1+\frac{A_{0}(i)}{\varepsilon_{2} z(i)}\right] z(i) d F(i) \\
& +\frac{\varepsilon_{2}-\varepsilon_{1}}{\varepsilon_{2}} \int_{-\varepsilon_{1} z(i) \leq A_{0}(i)<0}\left(-\frac{A_{0}(i)}{\varepsilon_{1} z(i)}\right) z(i) d F(i)
\end{aligned} \geq 0,
$$

because $1+\frac{A_{0}(i)}{\varepsilon_{2} z(i)} \geq 0$ for $-\varepsilon_{2} z(i) \leq A_{0}(i)$ so the first integral is non-negative, $-\frac{A_{0}(i)}{\varepsilon_{1} z(i)}>0$ for $A_{0}(i)<0$ so the second integral is non-negative, and $\frac{\varepsilon_{2}-\varepsilon_{1}}{\varepsilon_{2}}>0$. Therefore, $\theta(\varepsilon)$ is (weakly) decreasing in $\varepsilon$ for $\varepsilon>0$.

Now consider $\varepsilon_{2}<\varepsilon_{1}<0$. Use the expression for $\theta(\varepsilon)$ in Lemma 2 to obtain

$$
\theta(\varepsilon)=\frac{1}{\varepsilon} \int_{0 \leq A_{0}(i)<-\varepsilon z(i)} A_{0}(i) d F(i)+\int_{A_{0}(i)<-\varepsilon z(i)} z(i) d F(i), \quad \text { for } \varepsilon<0 .
$$

Evaluate $\theta(\varepsilon)$ at $\varepsilon_{1}$ and $\varepsilon_{2}$ and rearrange to obtain

$$
\theta\left(\varepsilon_{1}\right)=\frac{1}{\varepsilon_{1}} \int_{0 \leq A_{0}(i)<-\varepsilon_{1} z(i)} A_{0}(i) d F(i)+\int_{A_{0}(i)<-\varepsilon_{1} z(i)} z(i) d F(i)
$$

and

$$
\begin{aligned}
\theta\left(\varepsilon_{2}\right)= & \frac{1}{\varepsilon_{2}} \int_{0 \leq A_{0}(i)<-\varepsilon_{2} z(i)} A_{0}(i) d F(i)+\int_{A_{0}(i)<-\varepsilon_{2} z(i)} z(i) d F(i) \\
= & \frac{1}{\varepsilon_{2}}\left(\int_{0 \leq A_{0}(i)<-\varepsilon_{1} z(i)} A_{0}(i) d F(i)+\int_{-\varepsilon_{1} z(i) \leq A_{0}(i)<-\varepsilon_{2} z(i)} A_{0}(i) d F(i)\right) \\
& +\int_{A_{0}(i)<-\varepsilon_{2} z(i)} z(i) d F(i) .
\end{aligned}
$$

Subtract $\theta\left(\varepsilon_{1}\right)$ from $\theta\left(\varepsilon_{2}\right)$ and rearrange to obtain

$$
\begin{aligned}
\theta\left(\varepsilon_{2}\right)-\theta\left(\varepsilon_{1}\right)= & \left(\frac{1}{\varepsilon_{2}}-\frac{1}{\varepsilon_{1}}\right) \int_{0 \leq A_{0}(i)<-\varepsilon_{1} z(i)} A_{0}(i) d F(i) \\
& +\frac{1}{\varepsilon_{2}} \int_{-\varepsilon_{1} z(i) \leq A_{0}(i)<-\varepsilon_{2} z(i)} A_{0}(i) d F(i) \\
& +\int_{-\varepsilon_{1} z(i) \leq A_{0}(i)<-\varepsilon_{2} z(i)} z(i) d F(i) .
\end{aligned}
$$

To show that $\theta\left(\varepsilon_{2}\right)-\theta\left(\varepsilon_{1}\right) \geq 0$, it suffices to show that $\frac{1}{\varepsilon_{2}}-\frac{1}{\varepsilon_{1}}>0$ for $\varepsilon_{2}<\varepsilon_{1}<0$. Observe that $\frac{1}{\varepsilon_{2}}-\frac{1}{\varepsilon_{1}}=\frac{\varepsilon_{1}-\varepsilon_{2}}{\varepsilon_{1} \varepsilon_{2}}$ and the numerator $\varepsilon_{1}-\varepsilon_{2}$ is positive and the denominator $\varepsilon_{1} \varepsilon_{2}$ is also positive when $\varepsilon_{2}<\varepsilon_{1}<0$. Therefore, $\theta\left(\varepsilon_{2}\right)-\theta\left(\varepsilon_{1}\right) \geq 0$, so $\theta(\varepsilon)$ is (weakly) decreasing in $\varepsilon$ for $\varepsilon<0$.

Proof. of Proposition 3. First consider the case with $\varepsilon>0$. Substitute equation (14) into the defintion of the crowding-out coefficient to obtain

$$
\theta(\varepsilon)=G(-\varepsilon ; Z)+\int_{-\varepsilon z(i) \leq A_{0}(i)<0} \frac{-A_{0}(i)}{\varepsilon z(i)} z(i) d F(i) .
$$


Since $0<\frac{-A_{0}(i)}{\varepsilon z(i)} \leq 1$ for $-\varepsilon z(i) \leq A_{0}(i)<0$, it follows that

$$
0 \leq \int_{-\varepsilon z(i) \leq A_{0}(i)<0} \frac{-A_{0}(i)}{\varepsilon z(i)} z(i) d F(i) \leq \int_{-\varepsilon z(i) \leq A_{0}(i)<0} z(i) d F(i)
$$

and hence

$$
\begin{aligned}
0 & \leq \lim _{\varepsilon \searrow 0} \int_{-\varepsilon z(i) \leq A_{0}(i)<0} \frac{-A_{0}(i)}{\varepsilon z(i)} z(i) d F(i) \\
& \leq \lim _{\varepsilon \backslash 0} \int_{-\varepsilon z(i) \leq A_{0}(i)<0} z(i) d F(i)=0 .
\end{aligned}
$$

Therefore, $\lim _{\varepsilon \backslash 0} \int_{-\varepsilon z(i) \leq A_{0}(i)<0} \frac{-A_{0}(i)}{\varepsilon z(i)} z(i) d F(i)=0$ and hence $\theta\left(0^{+}\right) \equiv$ $\lim _{\varepsilon \backslash 0} \theta(\varepsilon)=\lim _{\varepsilon \backslash 0} G(-\varepsilon ; Z)=G(0 ; Z)$.

Next consider the case with $\varepsilon<0$. Substitute equation (15) into the definition of the crowding-out coefficient to obtain

$$
\theta(\varepsilon)=G(-\varepsilon ; Z)+\int_{0 \leq A_{0}(i)<-\varepsilon z(i)} \frac{A_{0}(i)}{\varepsilon z(i)} z(i) d F(i) .
$$

Since $-1<\frac{A_{0}(i)}{\varepsilon z(i)} \leq 0$ for $0 \leq A_{0}(i)<-\varepsilon z(i)$, it follows that

$$
0 \geq \int_{0 \leq A_{0}(i)<-\varepsilon z(i)} \frac{A_{0}(i)}{\varepsilon z(i)} z(i) d F(i)>-\int_{-\varepsilon z(i) \leq A_{0}(i)<0} z(i) d F(i)
$$

and hence

$$
\begin{aligned}
0 & \geq \lim _{\varepsilon \nearrow 0} \int_{0 \leq A_{0}(i)<-\varepsilon z(i)} \frac{A_{0}(i)}{\varepsilon z(i)} z(i) d F(i) \\
& \geq-\lim _{\varepsilon \nearrow 0} \int_{-\varepsilon z(i) \leq A_{0}(i)<0} z(i) d F(i)=0 .
\end{aligned}
$$

Therefore, $\lim _{\varepsilon \nearrow 0} \int_{0 \leq A_{0}(i)<-\varepsilon z(i)} \frac{A_{0}(i)}{\varepsilon z(i)} z(i) d F(i)=0$ and hence $\theta\left(0^{-}\right) \equiv \lim _{\varepsilon} \nearrow_{0} \theta(\varepsilon)$ $=\lim _{\varepsilon \nearrow 0} G(-\varepsilon ; Z)=\lim _{\varepsilon \backslash 0} G(\varepsilon ; Z) \equiv G\left(0^{+} ; Z\right)$.

Proof. of Proposition 4. Divide both sides of equation (19) by $\overline{b^{+}}$and use the definition of $\lambda$ to obtain $G(0 ; \mathbf{1}) \lambda=1-G\left(0^{+} ; \mathbf{1}\right)$. Next use the definition of $\omega_{0}$ to obtain $G(0 ; \mathbf{1}) \lambda=1-\omega_{0}-G(0 ; \mathbf{1})$, which implies $(1+\lambda) G(0 ; \mathbf{1})=$ $1-\omega_{0}$, and hence $G(0 ; \mathbf{1})=\frac{1-\omega_{0}}{1+\lambda}$. Proposition 3 implies that when $Z=\mathbf{1}$, $\theta\left(0^{+}\right)=G(0 ; \mathbf{1})$, which implies $\theta\left(0^{+}\right)=\frac{1-\omega_{0}}{1+\lambda}$. To calculate $\theta\left(0^{-}\right)$, once again use the definition of $\omega_{0}$ to rewrite $G(0 ; \mathbf{1}) \lambda=1-G\left(0^{+} ; \mathbf{1}\right)$, but eliminate $G(0 ; \mathbf{1})$ rather than $G\left(0^{+} ; \mathbf{1}\right)$, to obtain $\left(G\left(0^{+} ; \mathbf{1}\right)-\omega_{0}\right) \lambda=1-G\left(0^{+} ; \mathbf{1}\right)$, which implies $G\left(0^{+} ; \mathbf{1}\right)=\frac{1+\omega_{0} \lambda}{1+\lambda}$. Proposition 3 implies that when $Z=\mathbf{1}$, $\theta\left(0^{-}\right)=G\left(0^{+} ; \mathbf{1}\right)$, which implies $\theta\left(0^{-}\right)=\frac{1+\omega_{0} \lambda}{1+\lambda}$.

Proof. of Lemma 3. (by contradiction) Assume that $A(i)=A \geq 0$ for all $i$. Suppose that $b^{P}(i)>0$ for some households. Then $b^{P}(i)<0$ for some 
other households because some households can hold domestic privately-issued bonds only if some other households issue them. But Lemma 1 implies that $A(i)<0$ for households with $b^{P}(i)<0$, which contradicts the assumption that $A(i)=A \geq 0$ for all $i$. Therefore, $b^{P}(i) \leq 0$ for all households. Suppose that $b^{P}(i)<0$ for some households. Again, Lemma 1 implies that $A(i)<0$ for households with $b^{P}(i)<0$, which contradicts the assumption that $A(i)=A \geq 0$ for all $i$. Therefore, $b^{P}(i)$ cannot be negative for any households. Therefore, $b^{P}(i)=0$ for all $i$.

Proof. of Proposition 5. If $\varepsilon>0$, divide both sides of equation (27) by $\varepsilon$ and use Definition 3 to obtain

$$
\Theta_{N}(\varepsilon, \gamma)=(1-\gamma)\left(\begin{array}{c}
\int_{A_{0}(i)<-(1-\gamma) \varepsilon z(i)} z(i) d F(i) \\
-\int_{-(1-\gamma) \varepsilon z(i) \leq A_{0}(i)<0} \frac{A_{0}(i)}{(1-\gamma) \varepsilon z(i)} z(i) d F(i)
\end{array}\right), \text { if } \varepsilon>0
$$

Lemma 2 implies that for $\varepsilon>0$,

$$
\theta((1-\gamma) \varepsilon)=\quad \begin{gathered}
\int_{A_{0}(i)<-(1-\gamma) \varepsilon z(i)} z(i) d F(i) \\
+\int_{-(1-\gamma) \varepsilon z(i) \leq A_{0}(i)<0} \frac{-A_{0}(i)}{(1-\gamma) \varepsilon z(i)} z(i) d F(i)
\end{gathered}, \text { if } \varepsilon>0
$$

so $\Theta_{N}(\varepsilon, \gamma)=(1-\gamma) \theta((1-\gamma) \varepsilon)$, if $\varepsilon>0$.

If $\varepsilon<0$, divide both sides of equation (28) by $\varepsilon$ and use Definition 3 to obtain

$\Theta_{N}(\varepsilon, \gamma)=(1-\gamma)\left(\begin{array}{c}\int_{A_{0}(i)<-(1-\gamma) \varepsilon z(i)} z(i) d F(i) \\ +\int_{0 \leq A_{0}(i)<-(1-\gamma) \varepsilon z(i)} \frac{A_{0}(i)}{(1-\gamma) \varepsilon z(i)} z(i) d F(i)\end{array}\right), \quad$ if $\varepsilon<0$.

Lemma 2 implies that

$$
\theta((1-\gamma) \varepsilon)=\quad \begin{gathered}
\int_{A_{0}(i)<-(1-\gamma) \varepsilon z(i)} z(i) d F(i) \\
+\int_{0 \leq A_{0}(i)<-(1-\gamma) \varepsilon z(i)} \frac{A_{0}(i)}{(1-\gamma) \varepsilon z(i)} z(i) d F(i)
\end{gathered}, \quad \text { if } \varepsilon<0
$$

so $\Theta_{N}(\varepsilon, \gamma)=(1-\gamma) \theta((1-\gamma) \varepsilon)$, for $\varepsilon<0$. Therefore, $\Theta_{N}(\varepsilon, \gamma)=(1-\gamma) \theta((1-\gamma) \varepsilon)$, both for $\varepsilon>0$ and for $\varepsilon<0$.

Finally, $\Theta_{N}\left(0^{+}, \gamma\right) \equiv \lim _{\varepsilon \backslash 0} \Theta_{N}(\varepsilon, \gamma)=\lim _{\varepsilon \backslash 0}(1-\gamma) \theta((1-\gamma) \varepsilon)=(1-\gamma) \theta\left(0^{+}\right)$ and $\Theta_{N}\left(0^{-}, \gamma\right) \equiv \lim _{\varepsilon}{ }_{0} \Theta_{N}(\varepsilon, \gamma)=\lim _{\varepsilon}{ }_{0}(1-\gamma) \theta((1-\gamma) \varepsilon)=(1-\gamma) \theta\left(0^{-}\right)$. 


\section{References}

Barro, Robert J., "Are Government Bonds Net Wealth?" Journal of Political Economy, 82, 6 (November-December, 1974), 1095-1117.

Barro, Robert J. and Andrew Mollerus, "Safe Assets," National Bureau of Economic Research Working Paper 20652, October 2014.

Congressional Budget Office, The Distribution of Household Income and Federal Taxes, 2011, November 2014, Table 2 of file supplement downloaded from https://www.cbo.gov/sites/default/files/cbofiles/attachments/49440-Distributionof-Income-Taxes_Supplemental_0.xlsx on May 13, 2015.

Federal Reserve System, 2013 SCF Chartbook, September 2, 2014, (downloaded from http://www.federalreserve.gov/econresdata/scf/files/BulletinCharts.pdf)

Gorton, Gary, Stefan Lewellen, and Andrew Metrick, "The Safe-Asset Share," American Economic Review, Papers and Proceedings, 102, 3 (May 2012), 101106.

Krishnamurthy, Arvind and Annette Vissing-Jorgensen, "Short-term Debt and Financial Crises: What Can We Learn from U.S. Treasury Supply," unpublished, Northwestern University, 2013. 